\title{
P-Wave Imaging of the FRI and BK Zones at the Grimsel Rock Laboratory
}

\author{
Ernest L. Majer and John E. Peterson Jr. \\ Earth Sciences Division \\ Lawrence Berkeley Laboratory \\ University of California \\ Berkeley, California 94720 \\ Peter Blümling and Gerd Sattel \\ Swiss National Cooperative for the Storage of Nuclear Waste \\ Baden, Switzerland
}

August 1990

This work was supported by the Manager, Chicago Operations, Repository Technology Program, Repository Technology and Transportation Division, of the U.S. Department of Energy under Contract No. DEAC03-76SF00098 and by the Swiss National Cooperative for the Storage of Nuclear Waste (NAGRA). 


\section{Preface}

This report is one of a series documenting the results of the Nagra-DOE Cooperative (NDC-I) research program in which the cooperating scientists explore the geological, geophysical, hydrological, geochemical, and structural effects anticipated from the use of a rock mass as a geologic repository for nuclear waste. This program was sponsored by the U. S. Department of Energy (DOE) through the Lawrence Berkeley Laboratory (LBL) and the Swiss Nationale Genossenschaft fur die Lagerung radioaktiver Abfalla (Nagra) and concluded in September 1989. The principal investigators are Jane C. S. Long, Ernest L. Majer, Karsten Pruess, Kenzi Karasaki, Chalon Carnahan and Chin-Fu Tsang for LBL and Piet Zuidema, Peter Bllumling, Peter Hufschmied and Stratis Vomvoris for Nagra. Other participants will appear as authors of the individual reports. Technical reports in this series are listed below.

1. Determination of Fracture Inflow Parameters with a Borehole Fluid Conductivity Logging Method by Chin-Fu Tsang, Peter Hufschmied, and Frank V. Hale (NDC-1, LBL-24752).

2. A Code to Compute Borehole Fluid Conductivity Profiles with Multiple Feed Points by Frank V. Hale and Chin-Fu Tsang (NDC-2, LBL-24928; also NTB 88-21).

3. Numerical Simulation of Alteration of Sodium Bentonite by Diffusion of lonic Groundwater Components by Janet S. Jacobsen and Chalon L. Carnahan (NDC-3, LBL-24494).

4. P.Wave Imaging of the FRI and BK Zones at the Grimsel Rock Laboratory by Ernest L. Majer, John E. Peterson Jr., Peter Blumling, and Gerd Sattel (NDC-4, LBL-28807).

5. Numerical Modeling of Gas Migration at a Proposed Repository for Low and Intermediate Level Nuclear Wastes at Oberbauenstock, Switzerland by Karsten Pruess (NDC-5, LBL-25413).

6. Analysis of Well Test Data from Selected Intervals in Leuggern Deep Borehole - Verification and Application of PTST Method by Kenzi Karasaki (NDC-6, LBL-27914).

7. Shear Wave Experiments at the U. S. Site at the Grimsel Laboratory by Ernest L. Majer, John E. Peterson Jr., Peter Bltumling, and Gerd Sattel (NDC 7 LBL-28808).

8. The Application of Moment Methods to the Analysis of Fluid Electrical Conductivity Logs in Boreholes by Simon Loew, Chin-Fu Tsang, Frank V. Hale, and Peter Hufschmied (NDC-8, LBL28809).

9. Numerical Simulation of Cesium and Strontium Migration through Sodium Bentonite Altered by Cation Exchange with Groundwater Components by Janet S. Jacobsen and Chalon L. Camahan (NDC-9, LBL-26395).

10. Theory and Calculation of Water Distribution in Bentonite in a Thermal Ficld by Chalon L. Carnahan (NDC-10, LBL-26058).

11. Prematurely Terminated Slug Tests by Kenzi Karasaki (NDC-11, LBL-27528).

12. Hydrologic Characterization of Fractured Rocks - An Interdisciplinary Methodology by Jane C. S. Long, Ernest L. Majer, Stephen J. Martel, Kenzi Karasaki, John E. Peterson Jr., Amy Davey, and Kevin Hestir, (NDC-12, LBL-27863).

13. Exploratory Simulations of Multiphase Effects in Gas Injection and Ventilation Tests in an Underground Rock Laboratory by Stefan Finsterle, Erika Schlueter, and Karsten Pruess (NDC-13, LBL28810).

14. Joint Seisinic, Hytrogeological, and Geomechanical Investigations of a Fracture Zone in the Grimsel Rock Laboratory, Switzeriand by Ernest L. Majer, Larry R. Myer, John E. Pettrson Jr., Kenzi Karasaki, Jane C. S. Long, Stephen J. Martel, Peter Blumling, and Stratis Vomvoris (NDC-14, LBL27913).

15. Analysis of Hydraulic Data from the MI Fracture Zone at the Grimsel Rock Laboratory, Switzerland by Amy Davey, Kenzi Karasaki, Jane C.S. Long, Martin Landsfeld, Antoine Mensch, and Stephen J. Martel (NDC-15, LBL-27864).

16. Use of Integrated Geologic and Geophysical Information for Characterizing the Structure of Fracture Systems at the US/BK Site, Grimsel Laboratory, Swizerland by Stephen J. Martel and John E. Peterson Jr. (NDC-16, LBL-27912). 


$$
-v-1 / i
$$

\section{Table of Contents}

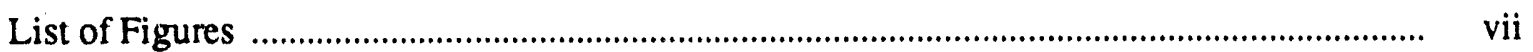

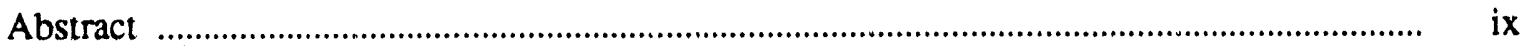

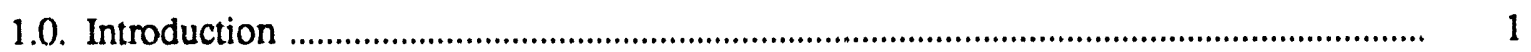

2.0. FRI Zone Experiments ...............................................................................................

3.0. BK Zone Experiments ..................................................................................................

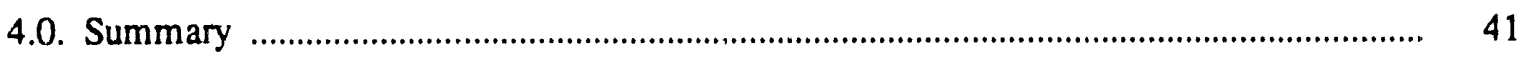

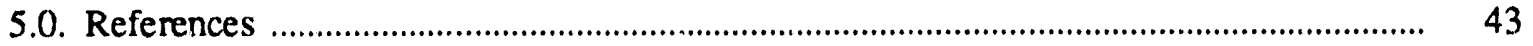




\section{-vilf}

\section{List of Figures}

Page

Figure 2.1. FRI experiment area of the Grimsel test facility. Shown are the locations of the boreholes and the fracture zones.

Figure 2.2. An expanded view of the FRI zone. The velocities shown are for intact core taken near the fracture zone in borehole 87.0033 .5 meters from the wall of the lab tunnel.

Figure 2.3. Typical example of the P-wave data acquired at the FRI zone.

Figure 2.4. Typical example of the S- $u$ ave data acquired at the FRI zone. Notice how the S-wave disappears as the fracture zone intersects the ray path.

Figure 2.5. Convention used for the source and receiver station used in the crosshole work at the FRI zone.

Figure 2.6. Plot of the travel times as a function of position for the cross borehole paths.

Figure 2.7. Plot of the travel times as a function of position for borehole 87.001 to the lab tunnel.

Figure 2.8. Plot of the travel times as a function of position for borehole 87.001 to the main or access tunnel.

Figure 2.9. Plot of the travel times as a function of position for borehole 87.002 to the lab tunnel.

Figure 2.10. Plot of the travel times as a function of position for borehole 87.002 to the main or access tunnel.

Figure 2.11. Plot of travel times as a function of distance for all of the P-wave data at the FRI zone. 
Figure 2.12. Plot of the velocity as a function of azimuth for all of the P-wave data at the FRI zone.

Figure 2.13. Ray paths used for the velocity inversion in Figure 14. in the FRI zone.

Figure 2.14. Resulting tomogram of the P-wave data for the FRI zone. The darkest is all velocities $4.6 \mathrm{~km} / \mathrm{sec}$ or slower, and the lightest is all velocities $5.2 \mathrm{~km} / \mathrm{sec}$ or faster.

Figure 2.15. Result of applying an anisotropy correction to the data and then inverting the data.

Figure 2.16. The raypaths used for the crosshole inversion. 25

Figure 2.17. The inversion results using crosshole paths only. 26

Figure 2.18. The ray paths used for crosshole plus the lab tunnel. 27

Figure 2.19. The inversion results using the raypaths in Figure 2.18. 28

Figure 2.20. The ray paths used for crosshole plus the access tunnel. 29

Figure 2.21. The inversion results using the raypaths in Figure 2.20. 30

Figure 3.1. Layout of the BK zone boreholes and the boreholes used for the 35 $\mathrm{P}$-wave studies in the BK zone.

Figure 3.2. Results of the P-wave velocity tomography in the BK zone. 36

Figure 3.3. Results of the P-wave amplitude tomography in the BK zone. 37 
$-\mathrm{ix}-$

\begin{abstract}
Tomographic imaging studies using a high frequency (10 Khz.) piezoelectric source and a three component receiver were carried out in two different regions of the underground Nagra Grimsel test facility in Switzerland. Both sites were in fractured granite, one being in a strongly foliated granite (FRI site), and the other being in a relatively homogeneous granite (BK zone). The object of the work was to determine if the seismic techniques could be usefun in imaging the fracture zones and provide information on the hydrologic conditions. Both amplitude and velocity tomograms were obtained from the data. The results indicate that the fracture zones strongly influenced the seismic wave propagation, thus imaging the fracture zones that were hydrologically important.
\end{abstract}




\subsection{Introduction}

As part of the United States Department of Energy (U. S. DOE) cooperative project with the National Cooperative for the Storage of Radioactive Waste (Nagra) of Switzerland, there have been a series of studies carried out at the Nagra underground test facility at Grimsel. The Grimsel test facility is several 3.5 meter diameter tunnels excavated with a tunnel boring machine in the southem Swiss Alps. The rock type is granitic, although there is a large variation in the granitic fabric throughout the facility. The work described here was the first phase of a multiyear project to evaluate and develop seismic imaging techniques for fracture detection and characterization for the use in siting underground nuclear waste facilities.

The problem of adequate fracture detection and characterization is essential to the accurate modeling of the hydrologic and geomechanical behavior of any underground nuclear waste repository. Fracture properties can be directly measured at the surface and underground openings, but because of the large variation in the geometry of fracture sets, it is unlikely that one can rely on the direct interpolation of structural information between boreholes for proper fracture characterization. Although there may be many fractures, or sets of fractures, the relative geomechanical or hydrologic contribution of the fractures may vary widely. Therefore, there is a crucial need to have techniques for fracture detection and characterization between boreholes. The problem of detection is very different from characterization. Detection may only involve the confirmation of the existence of fractures. Characterization ideally would be not only be the detection of the fractures, but would also define such parameters as orientation, density, aperture, degree of connection, and infilling material. In addition to the problem of characterization of a potential underground repository site, there is the problem of having a means for adequate performance confirmation. In order to address these problems one naturally tums to geophysical methods for solutions, i.e., the seismic and electrical methods. The work described here concerns seismic 
methods, but parallel developments are underway for the electrical methods both by Nagra and DOE.

As applied on a large scale to a repository environment the most likely borehole seismic method would be the multi-offset/Multi-source Vertical Seismic Profiling (VSP) from the surface and crosshole techniques in the underground workings. By performing a tomographic analysis of the VSP and crosshole data from multiple offsets ard azimuths, it may be possible to map the fracture content and structure. This data could then be used in hydrologic or geomechanical models of fracture networks to study the behavior of the rock mass. Seismic methods would then be used to provide a method for extrapolating fracture characteristics observable at the borehole walls and underground workings to the entire repository block, thus providing a more complete data set to characterize the overall hydrologic and geologic parameters.

Fracture detection using P- and S-waves in VSP studies is not a new idea, (Stewart et al., 1981). It is becoming increasingly apparent, however, that to utilize the full potential of VSP, 3component data should be acquired. Crampin has pointed oui the importance of using 3component data in VSP work, particularly for fracture detection (Crampin, 1978, 1981, 1984a, 1984b, 1985). These authors and others have pointed out the phenomenon of shear wave splitting and the anisotropy effects of SH-versus the SV- waves in addition to P-versus S-wave anisotropy (Leary and Henyey, 1985). in addition to Crampin's theoretical work un shear wave splitting $(1978,1985)$ there has been some recent laboratory (Hopkins et al., 1987) and theoretical work Schoenberg $(1980,1983)$ which explains seismic anisotropy in terms of fracture stiffness. The fracture stiffness theory differs from Crampin's theory in that at a fracture, or a non-welded interface, the displacement across the surface is not required to be continuous as a seismic wave passes. The only boundary condition in the solution to the wave equation is that the stress must remain continuous across an interface. This displacement discontinuity is taken to be linearly related to the stress through the stiffness of the discontinuity.

The implication of the fracture stiffness theory is that for very thin discontinuities, for example fractures, there can be significant effect upon the propagation of a wave. Usually one 
thinks of seismic resolution in terms of wavelength as compared to the thickness and lateral extent of a bed or other feature. In the stiffness theory the lateral extent is still important, but if the fracture stifiness is small enough the thickness of the feature can be much much less than the seismic wavelength. The effect should be even, nore pronounced in an unsaturated environment, such as at the DOE site at Yu cca Mountain, Nevada, because the stiffness of an unsaturated fracfure is less than that of a saturated fracture. Thus for any given size of fracture the lower limit of iracture detectability in an unsaturated fracture will be smaller than if the fracture is saturated. Alternatively, if the fractures are fairly uniform, it may be possible to map isolated saturated zones or perched water.

This stiffness theory is also attractive from several other points of view. Schoenberg $(1980,1983)$ shows that the ratio of the velocity of shear waves perpendicular and parallel to a set of siffness discontinuities is a function of the spacing of the discontinuities as well as the stiffness. Thus, given the stiffness and the velocity anisotropy, one may be able to determine the average fracture spacing or density. Or, alternatively, given independent information on fracture density, one could determine the fracture stiffness and hopefully relate this stiffness to actual fracture properties such as discriminating between filled and open fractures or hopefully hydraulic conductivity. In any case, there is sufficient reason to expect fracture content and properties to be reflected in the velocity, amplitude, and polarization of the seismic waves.

The FRI experiment area offers an excellent opportunity to perform calibrated experiments in a rock mass where the fracture locations and characteristics are relatively well known. Another advantage is that the access to the fracture zone is from all four sides which allow. comparison of techniques between two, three, and four sided tomography. The greatest attraction, however, is the opportunity to test the fracture stiffness theory and to evaluate this theory at different scales. As mentioned earlier, Hopkins et al. have performed laboratory experiments which have at small scales confirmed the effect of fracture stiffness. The scaling of this phenomenon to larger distances is yet unknown. Therefore, one of the main objectives of the FRI experiments is to observe the effect of fracture density, orientation and spacing on the propaga- 
tion of the P- and S-waves. A second objective is to relate the seismic response to the hydrologic behavior of the fractures, i.e., do all fractures effect the seismic wave, or do just fiuid filled, or partially saturated fractures effect the seismic waves in a measurable amount. Another objective of the study is to asses the amount of seismic data necessary to provide useful information, and how does one process these data for the maximum information in a routine fashion. These are important questions when one progresses to the point of applying these techniques on larger scalcs in a routine fashion. In addition to the work at the FRI site a smaller amount of work was carried out in the BK zone. This was because the BK zone was in a slightly different granite and because we wanted to test the techniques in the BK zone for possible future use. 


\subsection{FRI Zone Experiments}

Shown in Figures 2.1 and 2.2, nspectively, are the isometric view and plan views of the FRI zone. The FRI zone is at one end of the Grimsel test facility. It is adjacent to the migration test area (MI). There is a mylonitic fracture zone crossing the FRI zone. The boreholes were drilled to intersect this fracture zone as shown in the top half of Figure 2.1. As can be seen from Figure 2.1, there are other structural features in the same area. Three boreholes were drilled through the FRI zone. Boreholes 87.001 and 87.002 are $86 \mathrm{~mm}$ holes drilled from the lab tunnel to the access tunnel to provide a means of performing crosshole seismic work, core of the fracture zone, and for carrying out hydrologic experiments, (see Figure 2.2). Borehole 87.003 is a $127 \mathrm{~mm}$ hole drilled through the fracture zone for obtaining large core for laboratory analysis and also for hydrologic tasting. In addition to these holes, 76 shallow holes were drilled into the lab and access tunnel walls between boreholes 87.001 and 87.002 at 0.25 meter spacing to allow the placement of the seismic source and receivers. These shallow holes allowed the comparison of the various techniques between two, three, and four sided tomography by placing the three component source and receivers along the turinel walls.

The concept behind the FRI seismic experiments is relatively simple. P-and S-wave sources were placed in the holes (boreholes 87.001, 87.002, and the shallow roles in the sides of the tunnel) and activated. The data from a three component accelerometer package was recorded at 0.5 meter spacing in boreholes 87.001 and 87.002 . The receiver package was also placed in the shallow holes to give complete four sided coverage. The source and receiver package were clamped to the bore hole wall to provide good seismic coupling. The objective of the experiments was to gather high quality P-and S-wave data across the fracture zone to determine the seismic visibility of fractures. This controlled field data would then be compared to the results of the laboratory tests.. $\mathrm{n}$ the core. 

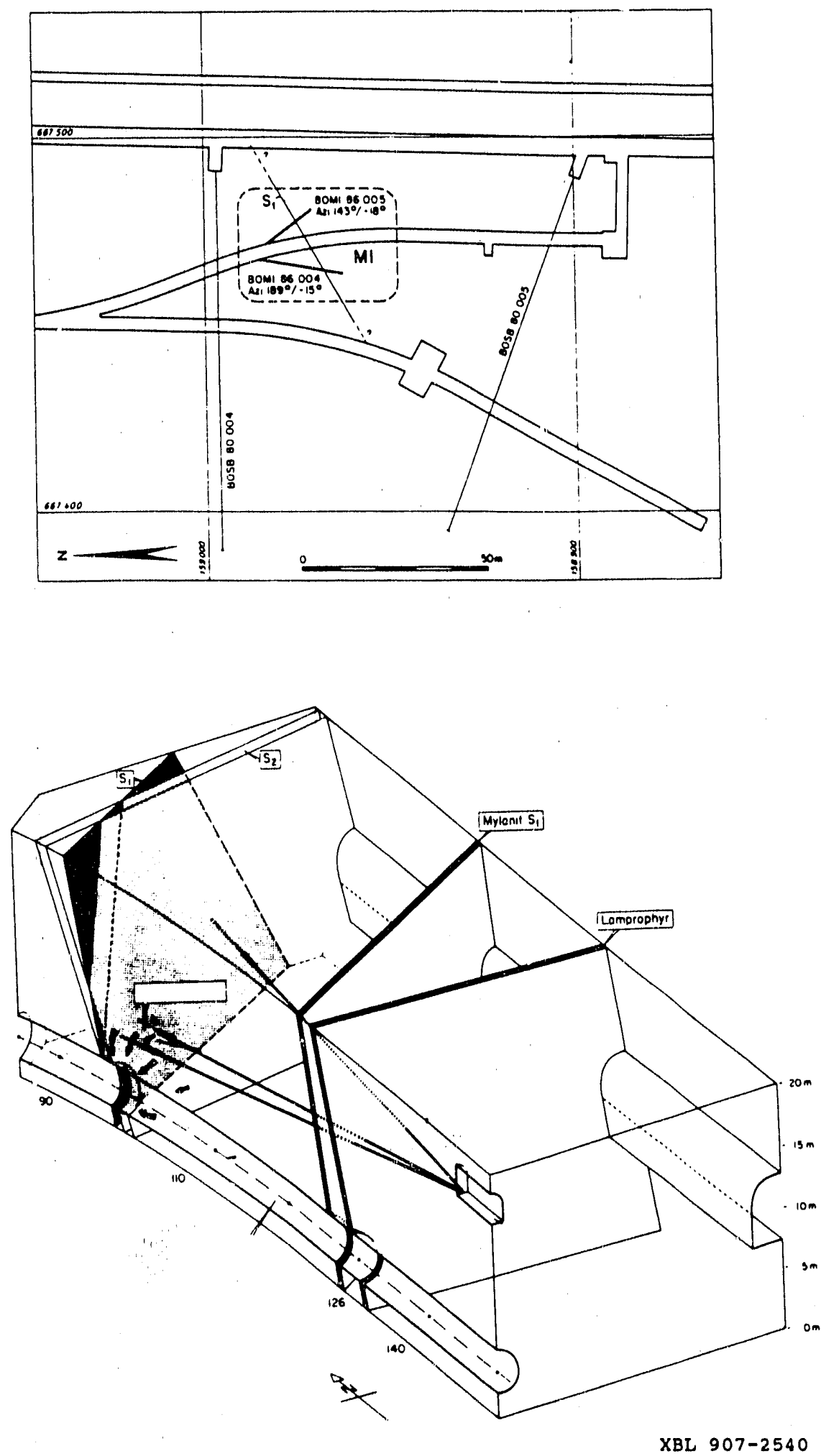

Figure 2.1. FRI experiment area of the Grimsel test facility. Shown are the locations of the boreholes and the fracture zones. 


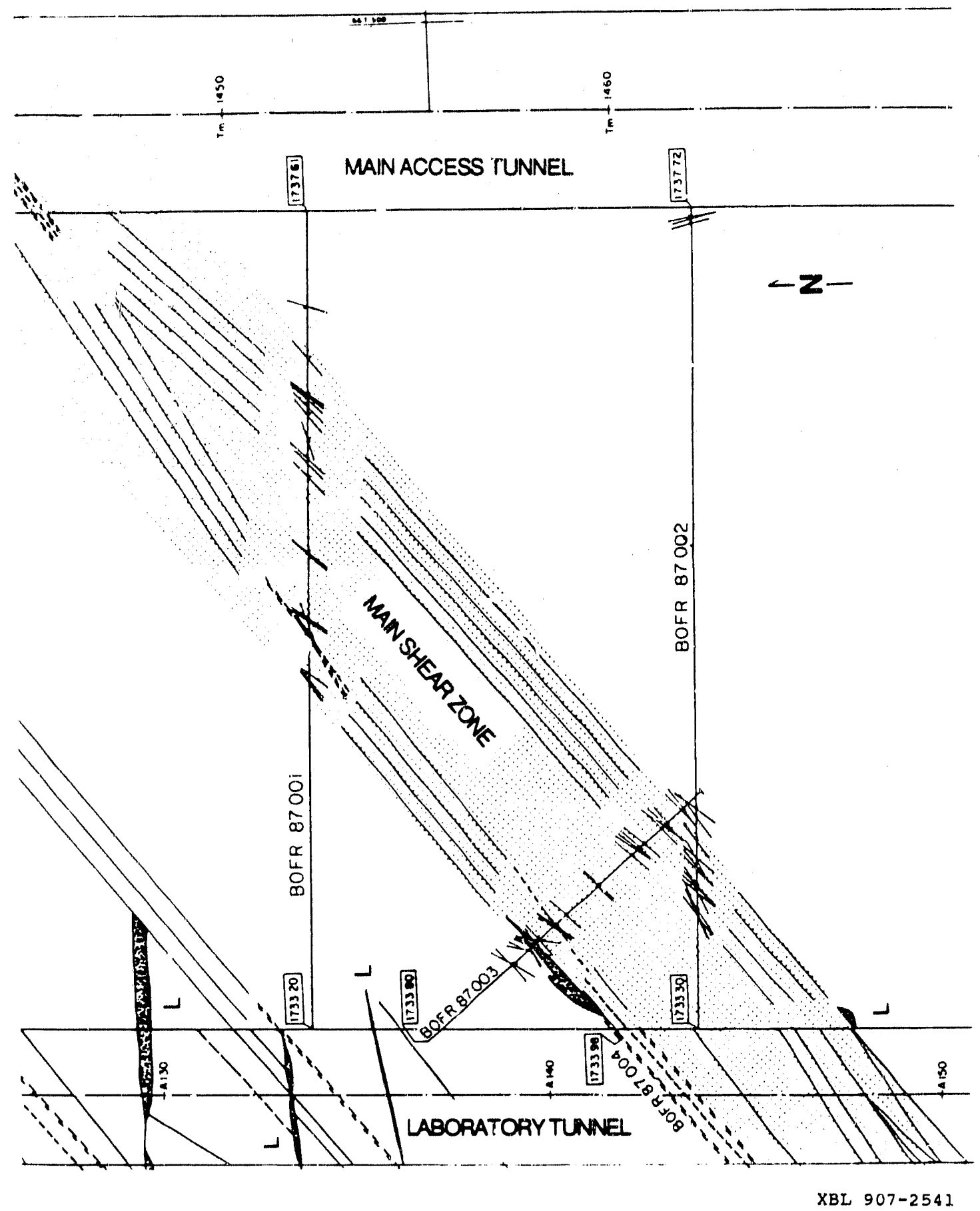

Figure 2.2. An expanded view of the FRI zone. The velocities shown are for intact core taken near the fracture zone in borehole 87.003 3.5 meters from the wall of the lab tunnel. 
The experiment was performed from: July 31 to August 31,1987 . In the FRI $z$ ine the spacing of the measurements in the boreholes ranged from $25 \mathrm{cmi}$ in the short boreholes in the tunnels to $50 \mathrm{~cm}$ in boreholes 87.001 and 87.002 . The data were recorded on an in-field PC-based acquisition system. Four channels of data "sere acquired, the $x, y$, and $z$ receivers and $t^{2}$. "trigger" signal. The sample rate was 50,000 samples/sec on each channel with 20 milliseconds of data being recorded for each channel. Four pole butterworth anti alias filters at $10 \mathrm{Khz}$ were used to condition the data before being digitized. Typical travel times were less than 5 milliseconds for the $\mathrm{P}$-wave and 10 milliseconds for the shear wave. Nearly 30,000 ray paths $(X, Y$, and $\mathrm{Z}$ components) were collected in the FRI zone, at distances from $1 / 2$ meter to nearly 23 meters. The peak ene:gy transmitted in the rock was $5,000 \mathrm{hz}$, thus yielding a wavelength of approximately 1 meter. Except for a few meetings with NAGRA personnel regarding the experiment progress and design, the entire time was spent collecting seismic tomography data. One day was spent, however, in mapping the fracture geonetry on the drift walls between the boreholes.

During the data collection we quickly realized that there were several fracture zones that were affecting the seismic waves. The highest quality data were derived from the borehole to borehole travel paths. The drift to borehole travel paths were significantly aff :ted by the damage zone near the walls. As will be seen later, this damage zone extends about 2 meters in from the lab tunnel and 3 to 4 meters for the access tunnel. Although the source was designed to generate S-waves as well as P-waves, it is obvious that the S-waves being generated the source used should be much stronger to penetrate the same distance as the P-waves. Therefore there was a very limited amount of shear wave data to process. This report will be only concerned with the analysis of the P-wave data.

Figures 2.3 and 2.4 show typical examples of the data. Figure 2.3 shows the P-wave data, and Figure 2.4 shows the S-wave data. As can be seen from these figures the P-wave data are much higher in quality than the S-wave data. First arrivals were picked as shown in Figure 2.3, on the first break. The arrivals were picked by simultaneously displaying from 10 to 20 traces at a 
RAIIAI, COMPONFNT

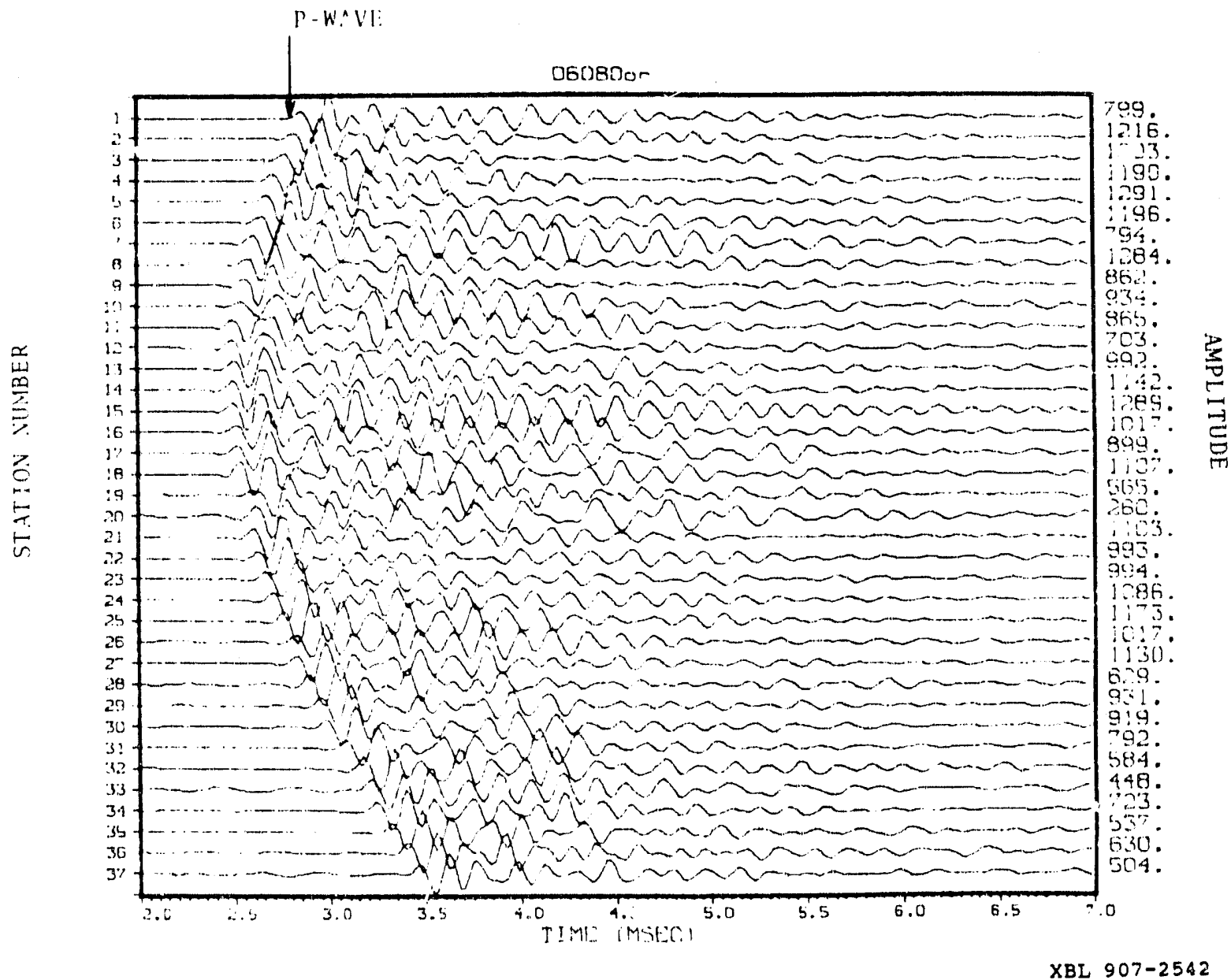

Figure 2.3. Typical example of the P-wave data acquired at the FRI zone. 


\section{Horizontal 2}

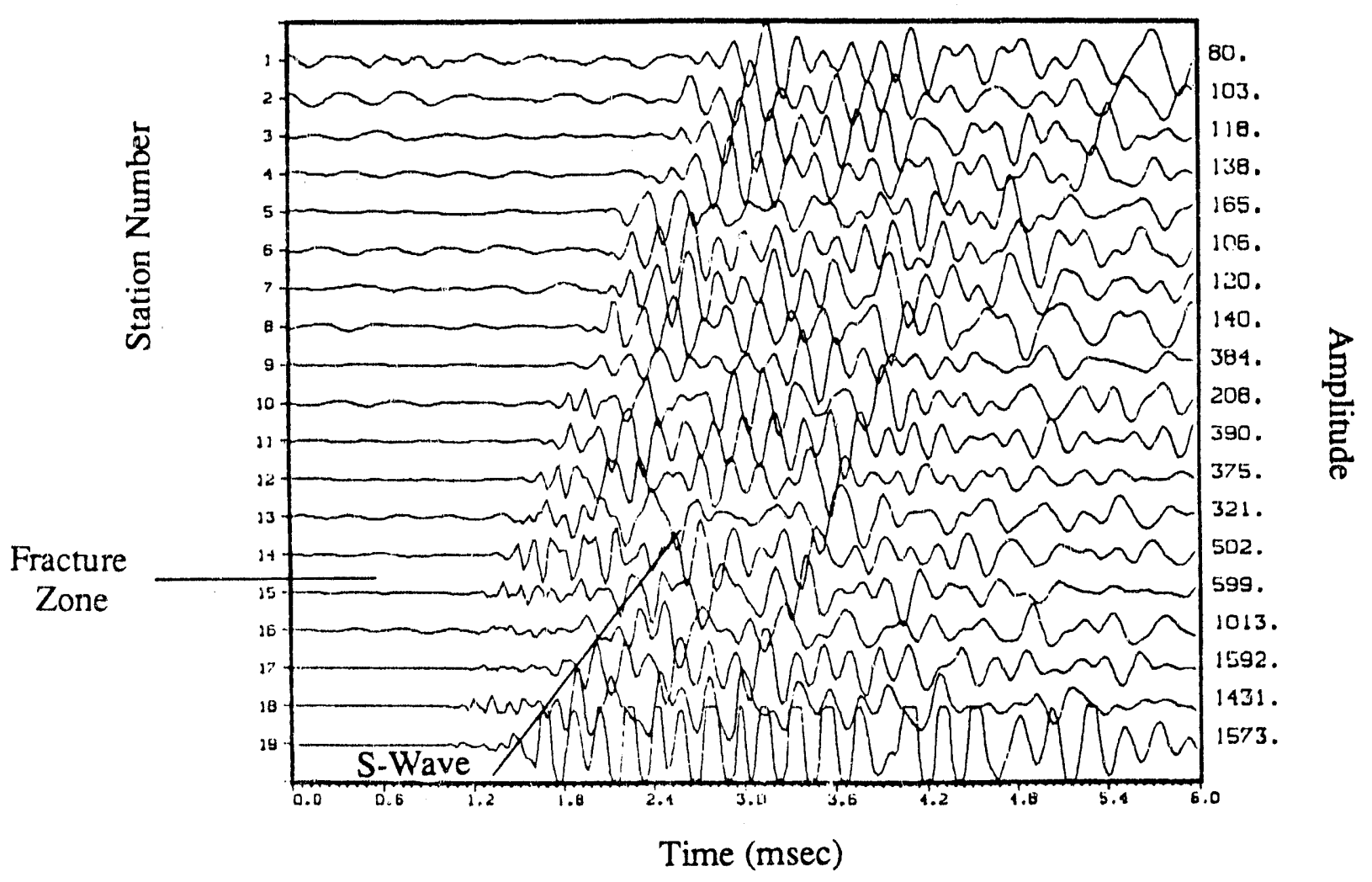

Figure 2.4. Typical example of the S-wave data acquired at the FRI zone. Notice how the $\mathrm{S}$-wave disappears as the fracture zone intersects the ray path. 
time on a high resolution graphics terminal (Tektronix 4114), and interactively picking the first break. All picks were by the same person, hopefully obtaining consistency in the picks. The accuracy of the picks is estimated to be about 0.08 milliseconds, or for the average travel path about three percent error. Figure 2.5 shows the convention used for the numbering of the receiver and source stations. Figures 2.6 through 2.10 are plots of the travel times for the various paths. From these plots one can pick out suspicious or bad picks by noting consistent deviation from the norm. One must be careful not to be too anxious to exclude data that may be due to real anomalies, ie very slow areas, or most likely in our case, a deviation of the source or receiver location from the expected position. One must also remember that these plots are not then same as time versus distance plots, these are time versus station plots. If the stations were all along smooth or straight lines one would not expect to see systematic variations in the plots, as in Figures 2.7 and 2.9. However, the stations located along the tunnels were not all in a straight line, but due to varying hole depths the stations were actually in a crooked line. This fact in itself made it sifficult to obtain accurate measurements, which also would contribute to the error. Looking at Figures 2.7 and 2.9 one sees systematic errors of .1 to .05 milliseconds. assuming that the velocity of the P-wave is 4.0 meters/sec, this would indicate that the distance difference is 20 to $40 \mathrm{~cm}$ between adjacent stations. This was the case in some instances due to the undulation in the tunnel wall and due to varying hole depths along the tunnel wall. If the systematic variations were due to geometry, rather than inaccurate picks, then one would expect to see the effect for each measurement at that station. This is not the case. For example, in Figure 2.9 at station 24 one can see a systematic "dip" in the data at this station. If it were due to geometry entirely one would expect to see it on all paths. Therefore, either the apparent velocity is compensating for the distance difference, or there is an erroneous pick. In any case we felt that the vast majority of the systematic differences were due to actual station geometry. Only eight of the picks in the whole data set were excluded.

Amplitude analysis was not carried out because we did not feel that the coupling was consistent enough in the dry holes. If the holes were water filled then we would have trusted the 


\section{Station Numbers}

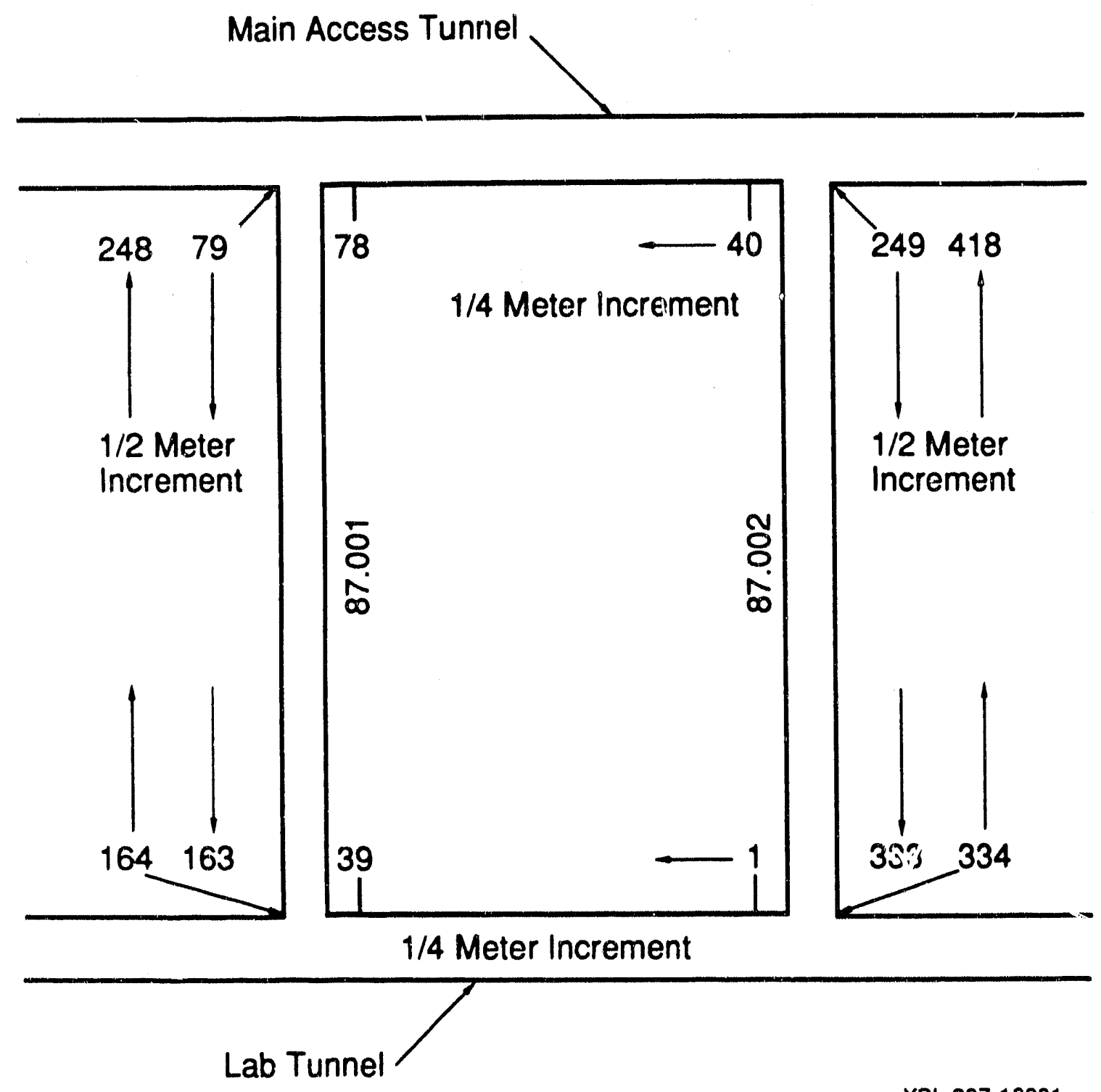

XBL. $887-10331$

Figure 2.5. Convention used for the source and receiver station used in the crosshole work at the FRI zone. 


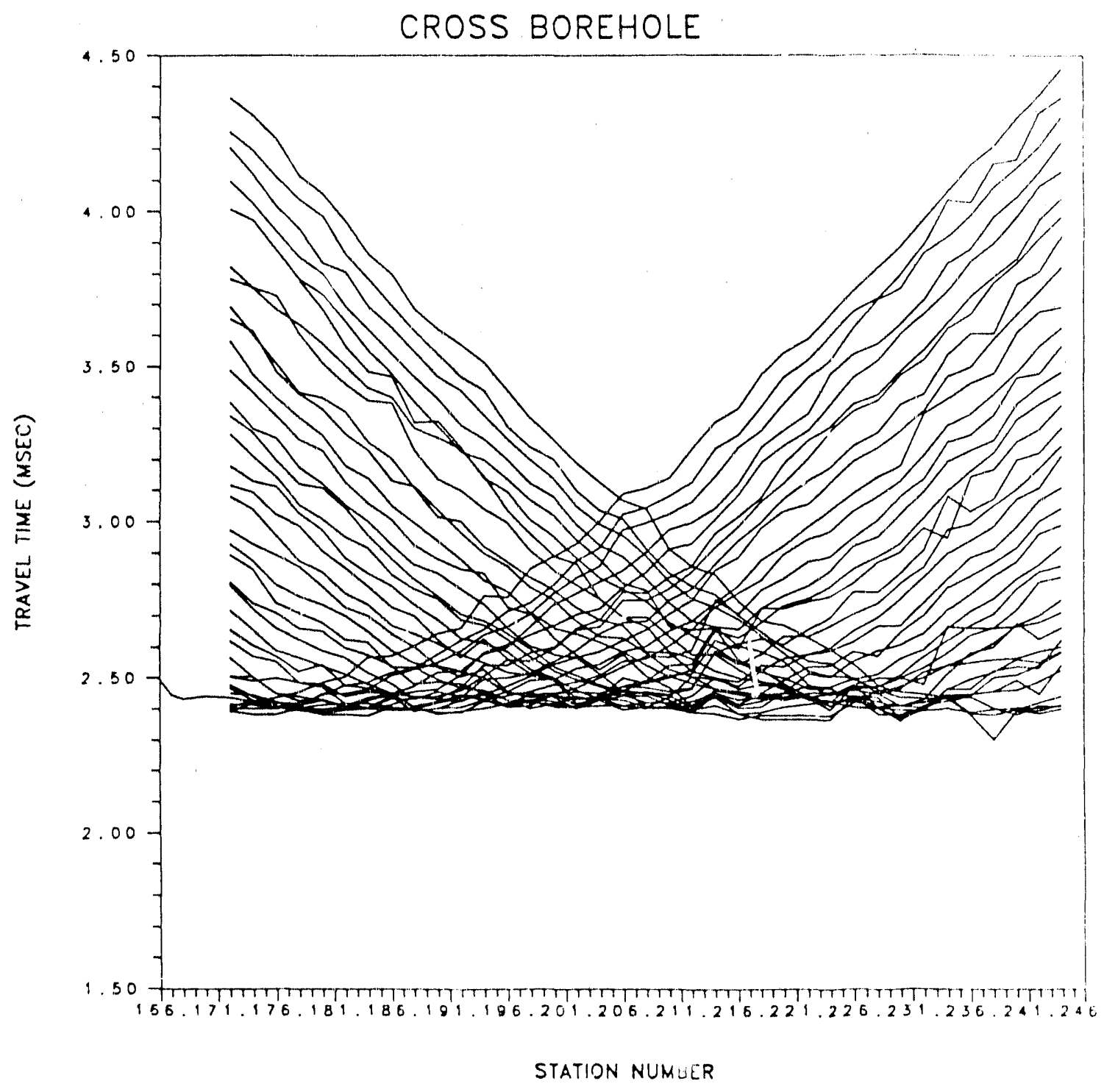

$X B L \quad 907-: 544$

Figure 2.6. Plot of the travel times as a funcion of position for the crnss borchole paths. 


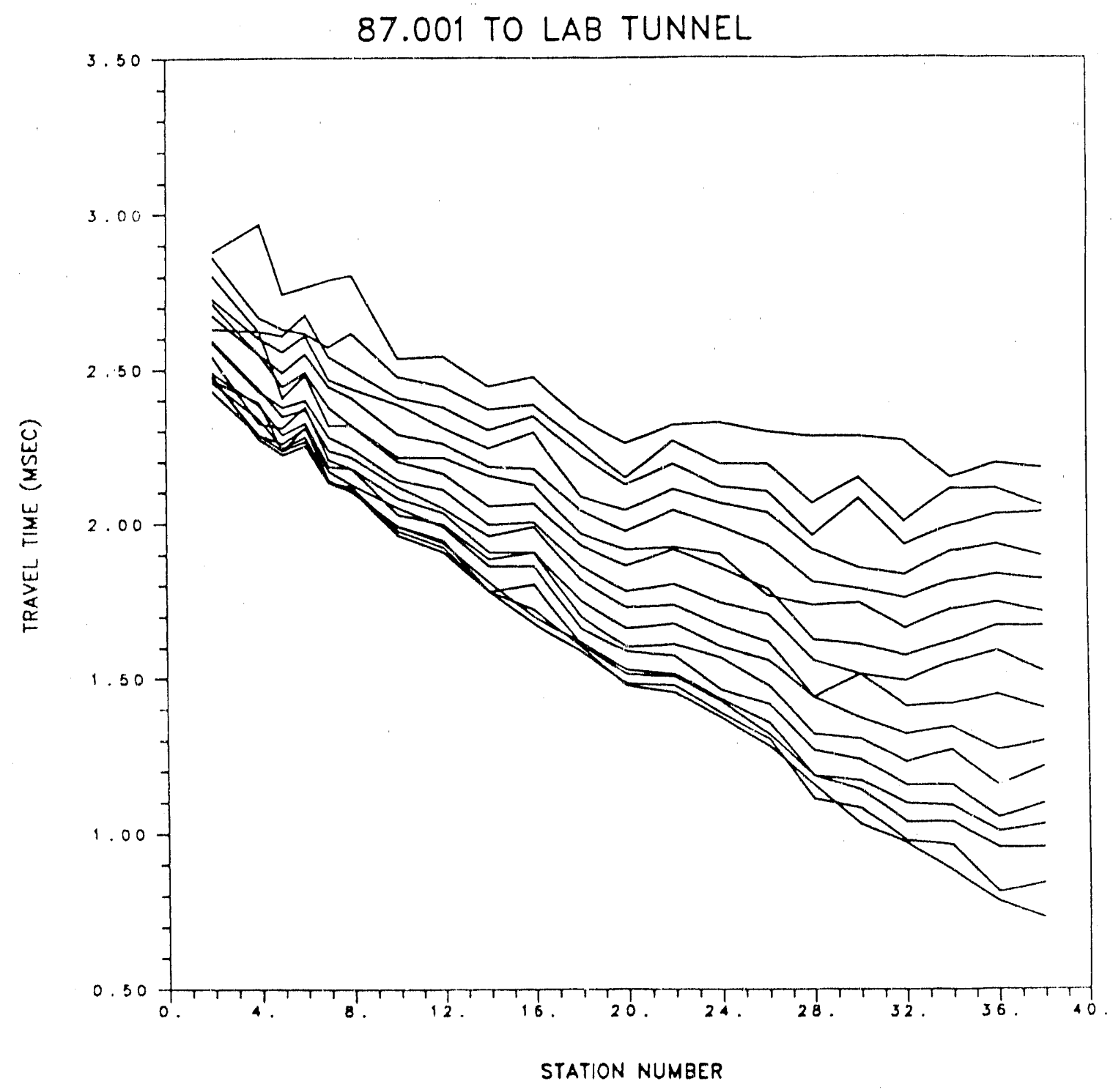

XBL $907-2545$

Figure 2.7. Plot of the travel times as a function of position for borehole 87.001 to the lab tunnel. 


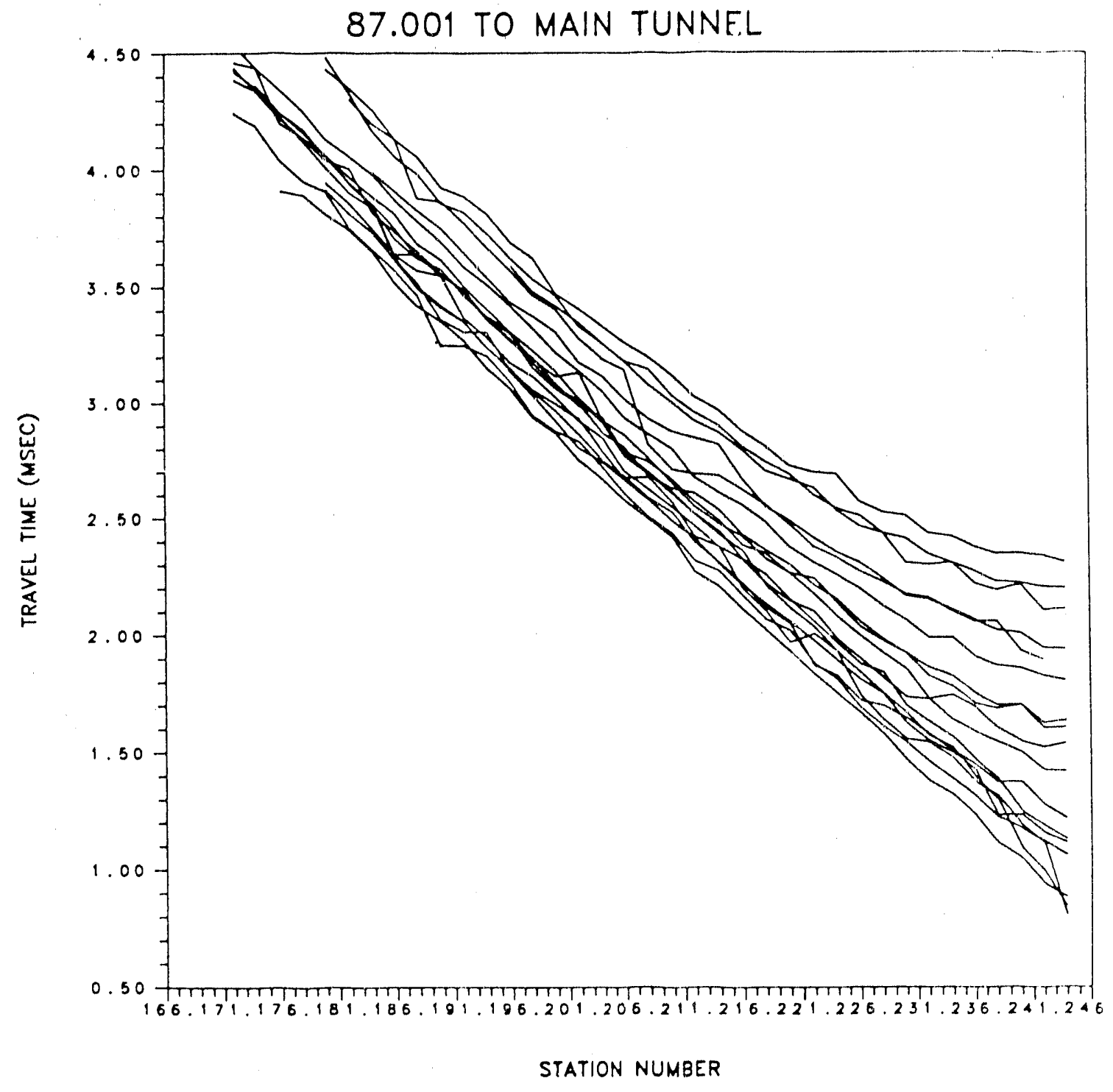

Figure 2.8. Plot of the travel times as a function of position for borchole 87.001 to the main or access tunnel. 


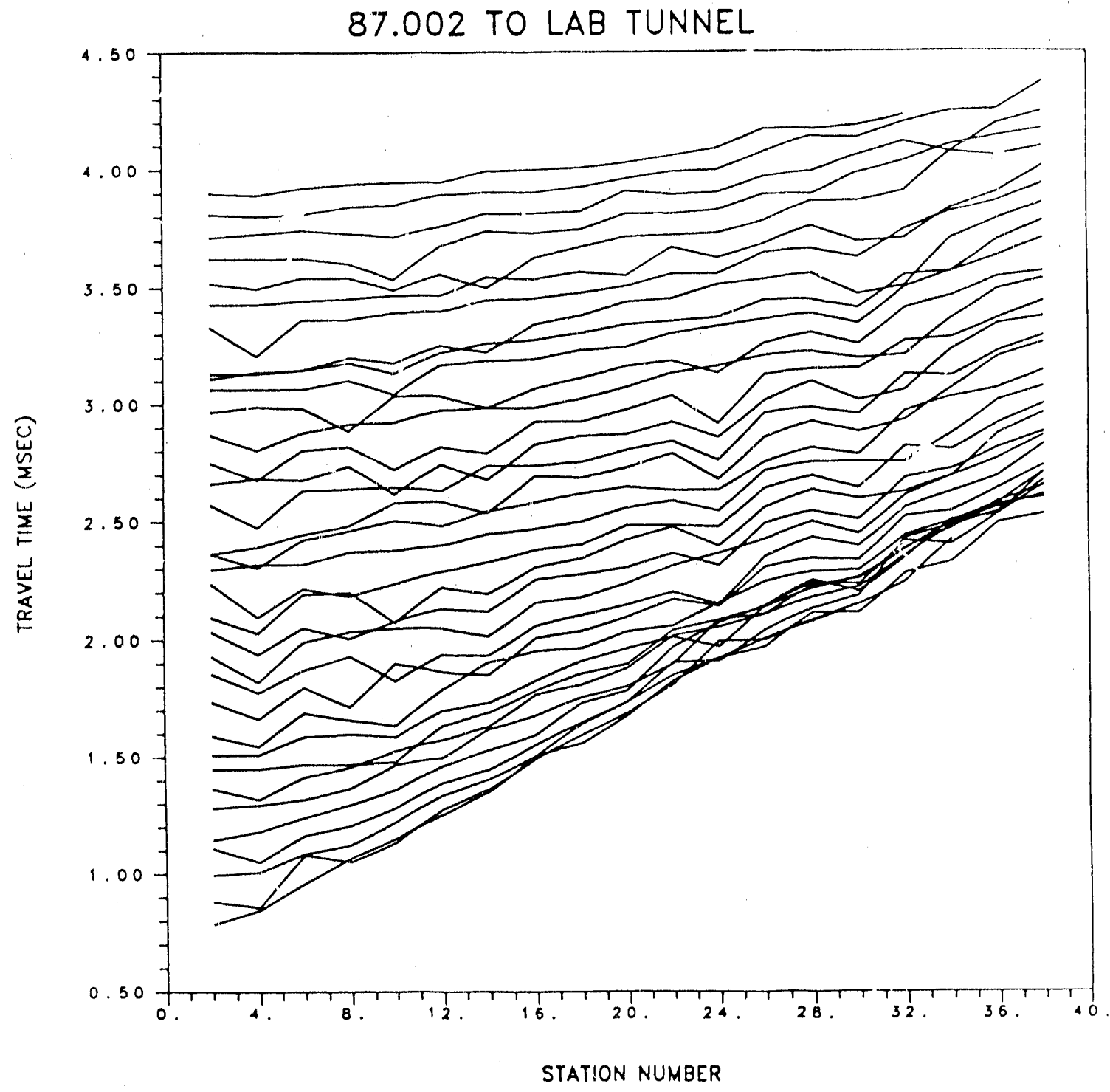

XBL $907-2547$

Figure 2.9. Plot of the travel times as a function of position for borehole 87.002 to the lab tunnel. 


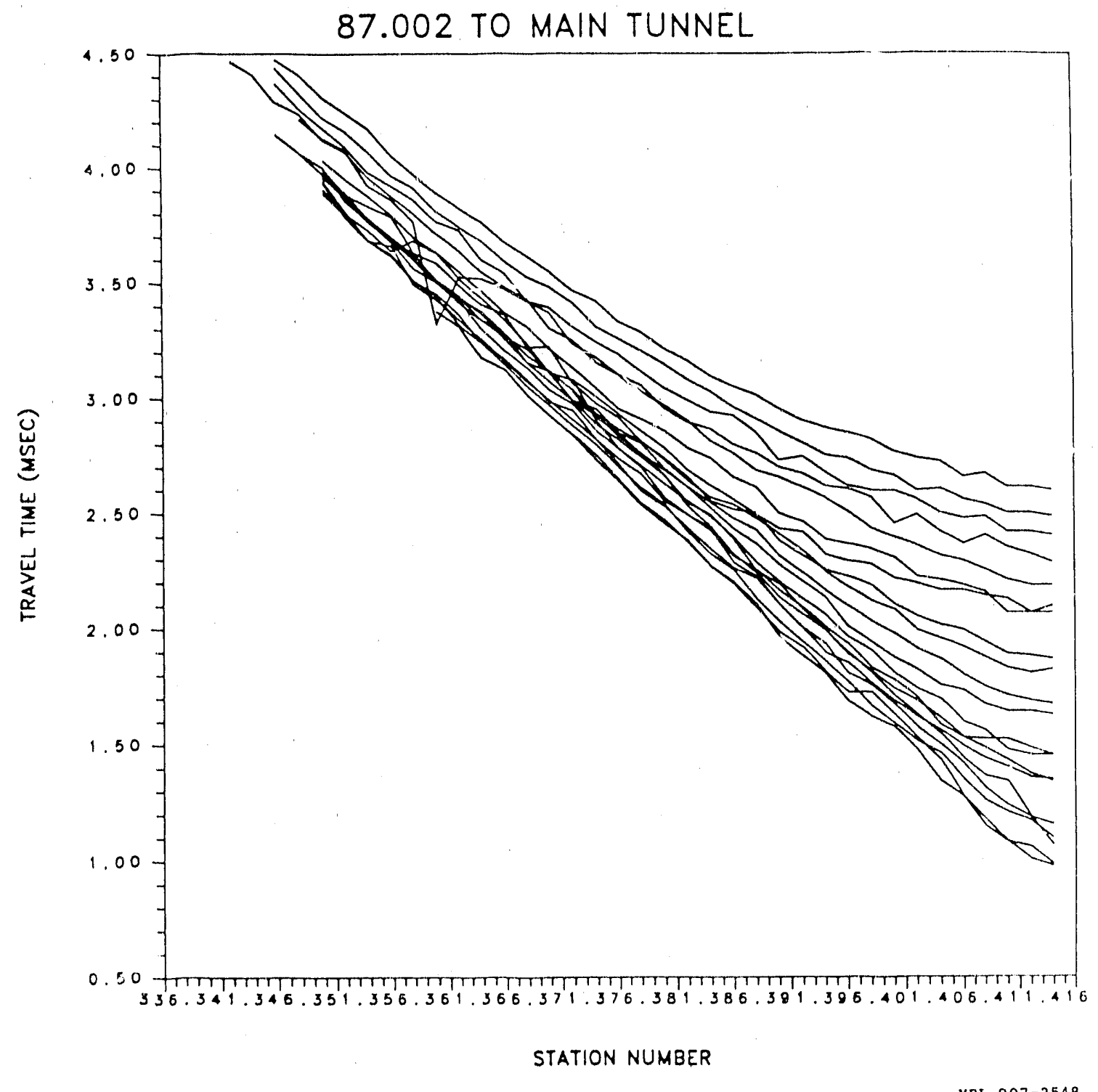

Figure 2.10. Plot of the travel times as a function of position for borchole 87.002 to the main or access tunnel. 
repeatability of coupling and thus the measurements.

Figure 2.11 is a composite of all the travel times as a function of distance. As can be seen they do not fall along a single ine, which would be expected for a homogeneous material. However, most of the scatter is due to the travel times corresponding to the tunnel stations. Figure 2.12 is a plot of the velocity of the P-wave as a function of angle, or an indication of the anisotropy of the area. The velocity varies from $4.6 \mathrm{~km} / \mathrm{sec}$ to almost $5.6 \mathrm{~km} / \mathrm{sec}$. There is a very large scatter in the data, again entirely due to the tunnel stations. The cross-borehole velocities were constrained to the crescent shape in the center of the plot. This gives an indication of a consistent velocity anisotropy varying from $4.9 \mathrm{~km} / \mathrm{sec}$ to $5.3 \mathrm{~km} / \mathrm{sec}$. However, when the anisotropy correction is used in the inversion, all the significant features are removed. Therefore, since satisfactory results were achicved without this correction, it was ignored.

An Algebraic Reconstruction Technique (ART) is used to perform the inversions. The ray paths for the complete four sided inversion is shown in Figure 2.13. This optimal geometry of this experiment produces a complete set of raypaths. We tested various pixel sizes and decided on an array of $44 \times 88$ giving a square pixel dimension of 0.25 meters. Larger pixels do not give satisfactory resolution while smaller pixels produce an excessive amount of smearing. Previous tests have shown the pixel sampling to correspond quite well to the resolution matrix of the least squares problem with greater sampling corresponding to resolvability of features. The root mean square (RMS) residual for the inversion is 0.08 milliseconds with only about 8 rays having travel times greater than 3 times this value.

The travel time inversion (Figure 2.14 ) shows a significant velocity contrast. The dominant features are the low velocity zones along the tunnels and the narrow zone extending from the lower tunnei to the middle of borehole 87.001. The tunnel-induced low velocity zones extend about 2.0 meters into the rock from the lower tunnel and a meter further from the upper sunnel, which is probably due to the fact that it was blasted instead of excavated with a tunnel boring machine (TBM). The velocities in this zone increase from less than $4.0 \mathrm{~km} / \mathrm{sec}$ at the tunnel to $5.3 \mathrm{~km} / \mathrm{sec}$ which is the velocity of the granitic mass. The most significant feature in the recon- 


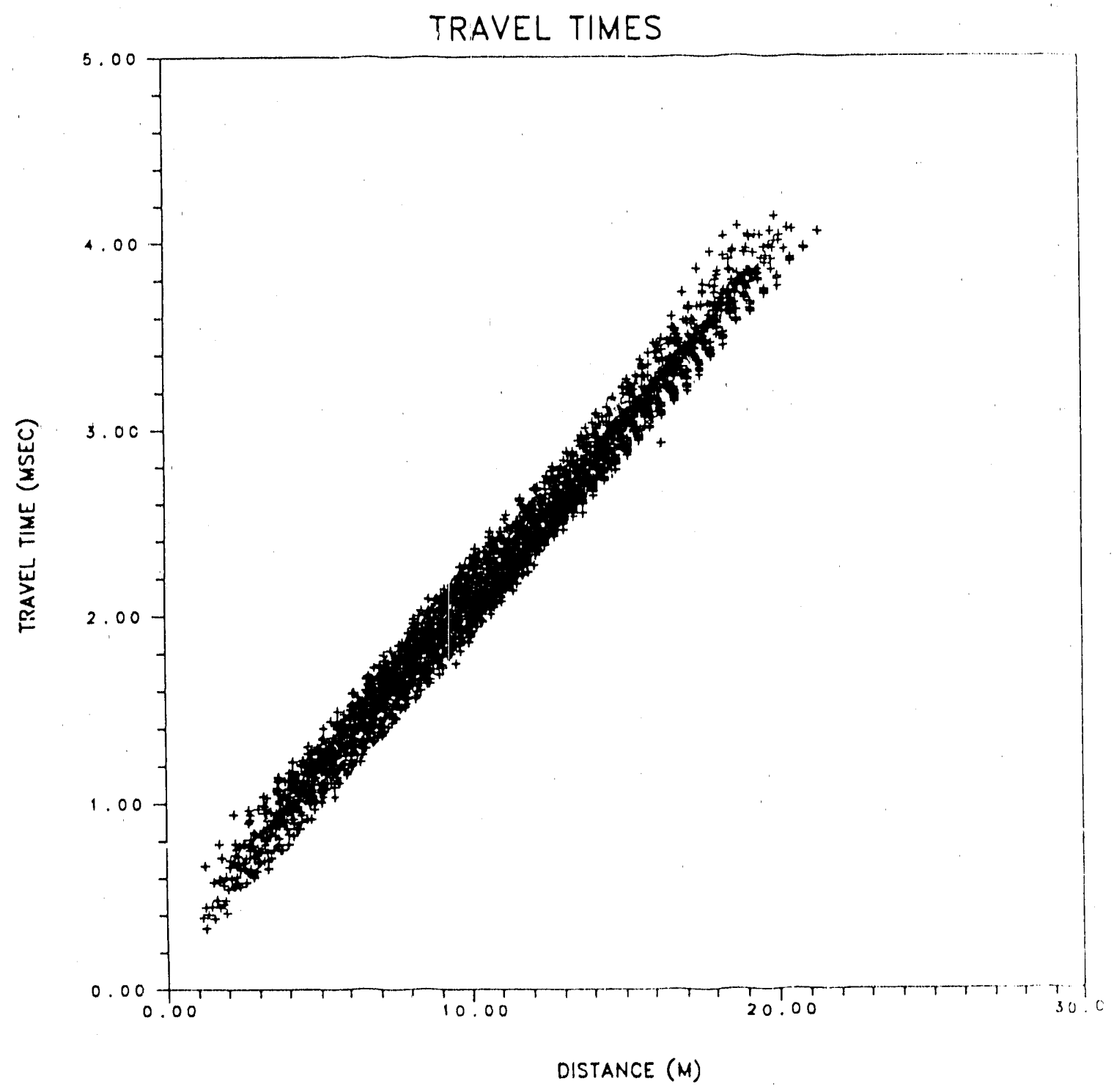

Figure 2.11. Plot of travel times as a function of distance for all of the P-wave data at the FRI zone. 


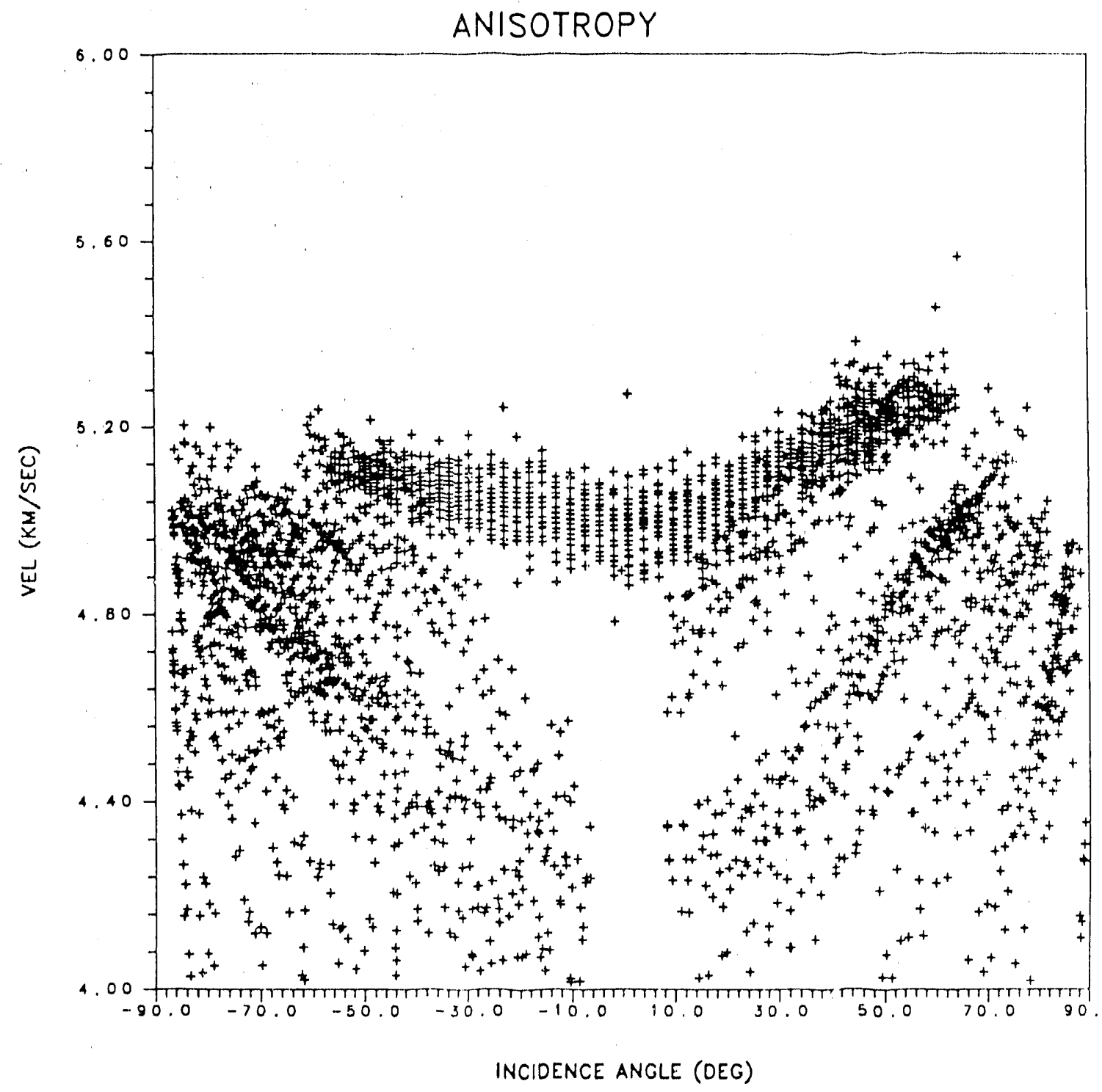

XBL $907-2550$

Figure 2.12. Plot of the velocity as a function of azimuth for all of the P-wave data at the FRI zone. 


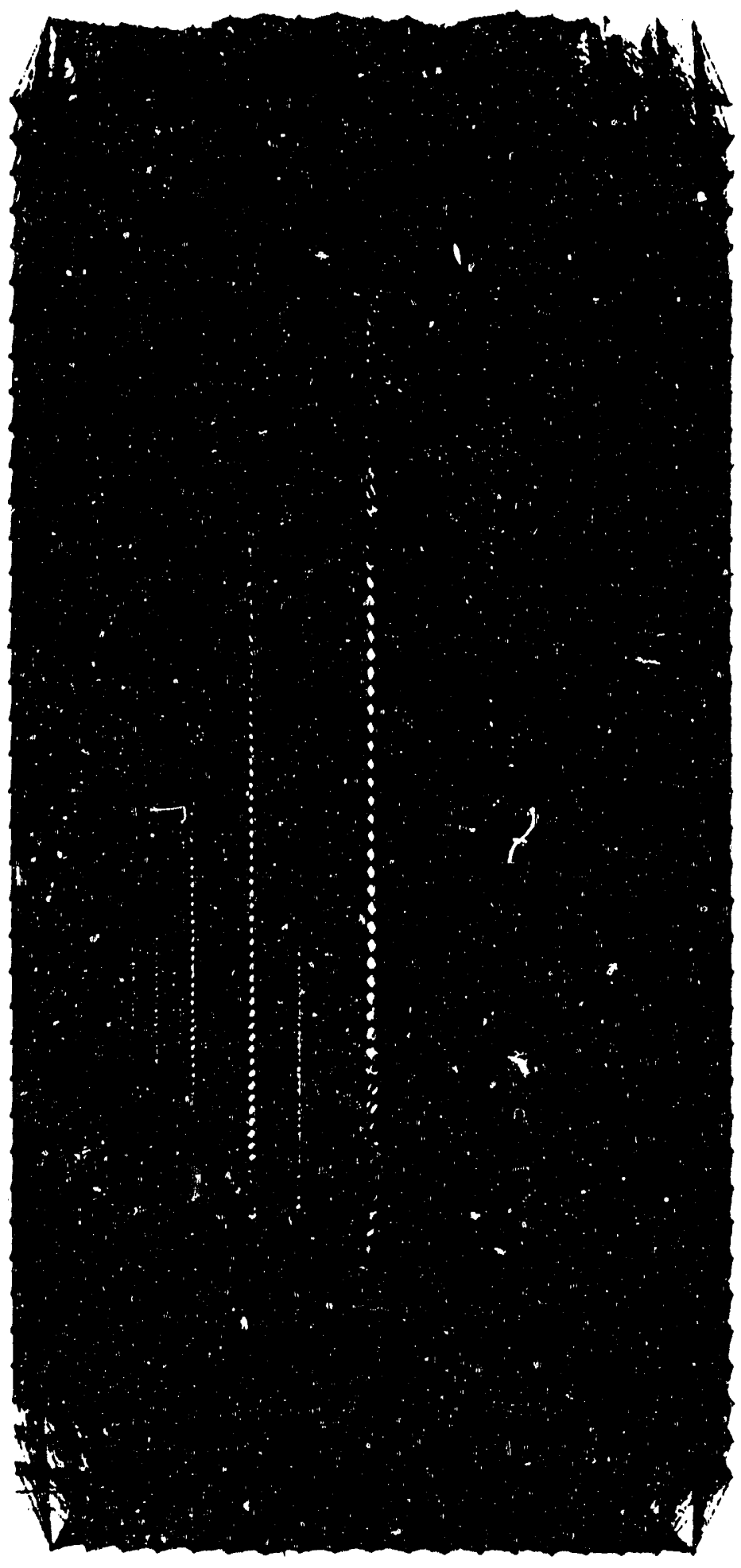

XBL 907-2551

Figure 2.13. Ray paths used for the velocity inversion in Figure 2.14 in the FRI zone. 


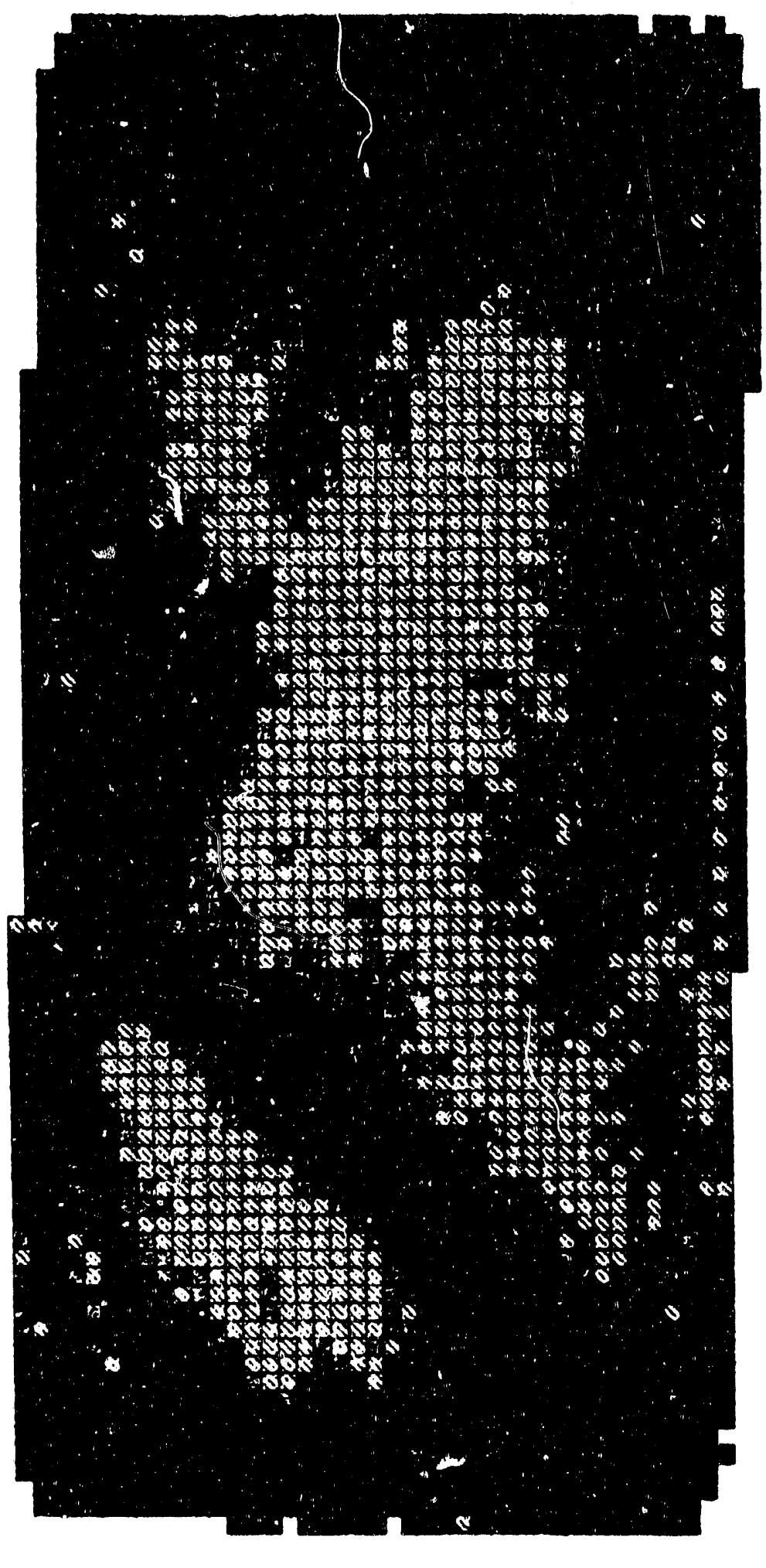

XBL $907-2552$

Figure 2.14. Resulting tomogram of the P-wave data for the FRI zone. The darkest is all velocities $4.6 \mathrm{~km} / \mathrm{sec}$ or slower, and the lightest is all velocities $5.2 \mathrm{~km} / \mathrm{sec}$ or faster. 
struction is the narrow low velocity zone corresponding to a significant open fraction in the fracture zone shown in Figure 2.2. The evidence for a single fracture interpretation includes the narrowness of the zone, the attenuation of S-waves across the fracture (Figure 2.4), and interpretation of the fractures themselves.

A secondary feature which produces average velocities somewhat greater than the features above, is the lo' / velocity zone in the upper right along borehole 87.002 . This feature, which does not seem to correspond to any fracture zones, is interpreted to be due to a lower velocity of the granite itself. Evidence for this comes from the velocity analysis of the core (NDC-14). This has shown that the "darker" granite has a higher velocity than the "lighter" granite. This velocity difference can be as large as 10 percent. The zone corresponding to the lower velocity is mostly comprised of this lighter color granite (see the report Photo-Dokumentation of BO FRI 87.001 and BO FRI 87.002).

It is interesting to note the results if the anisotropy results are taken into account. It is misleading to call the anisotropy results corrections to the data because in one sense it is the anisotropy that the fracture causes that we are hoping to image. The anisotropy that we hope to remove is the background anisotropy or matrix anisotropy that by eliminating, we may obtain a sharper image of the fracture structure. If anisotropy is removed from the data invertid in Figure 2.14 the result is Figure 2.15. The tendency is to minimize the smearing of features. In fact the image without the anisotropy "correction" applied seems to be more focused.

Figures 2.16 through 2.21 show the results of eliminating certain ray paths from the inversion. Figures 2.16 to 2.21 are the ray paths and images from the cross-hole case only, three sided using the crosshole and the lab tunnel, and three sided using the crosshole and access tunnel only, respectively. As expected the resolution is lost at the side where there is no coverage. It is interesting to note that for the three sicled cases the fracture zone is still imaged, however for the case of the rays coming from the access tunnel and the two boreholes, the image of the fracture is smeared with the lab tunnel low velocity zone. In any case it appears that for transmission 


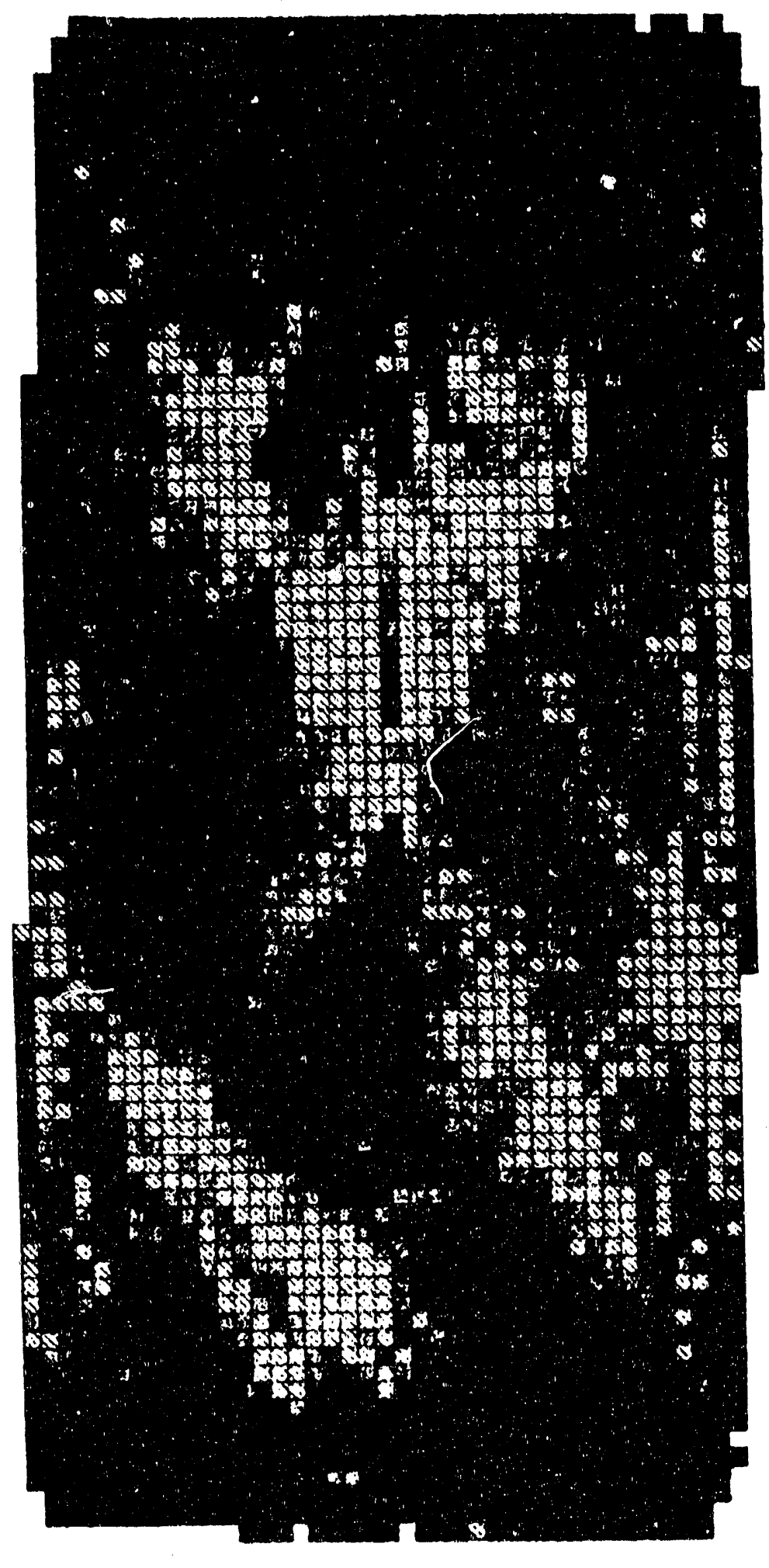

XBL $907-2553$

Figure 2.15. Result of applying an anisotropy correction to the data and then inverting the data. 


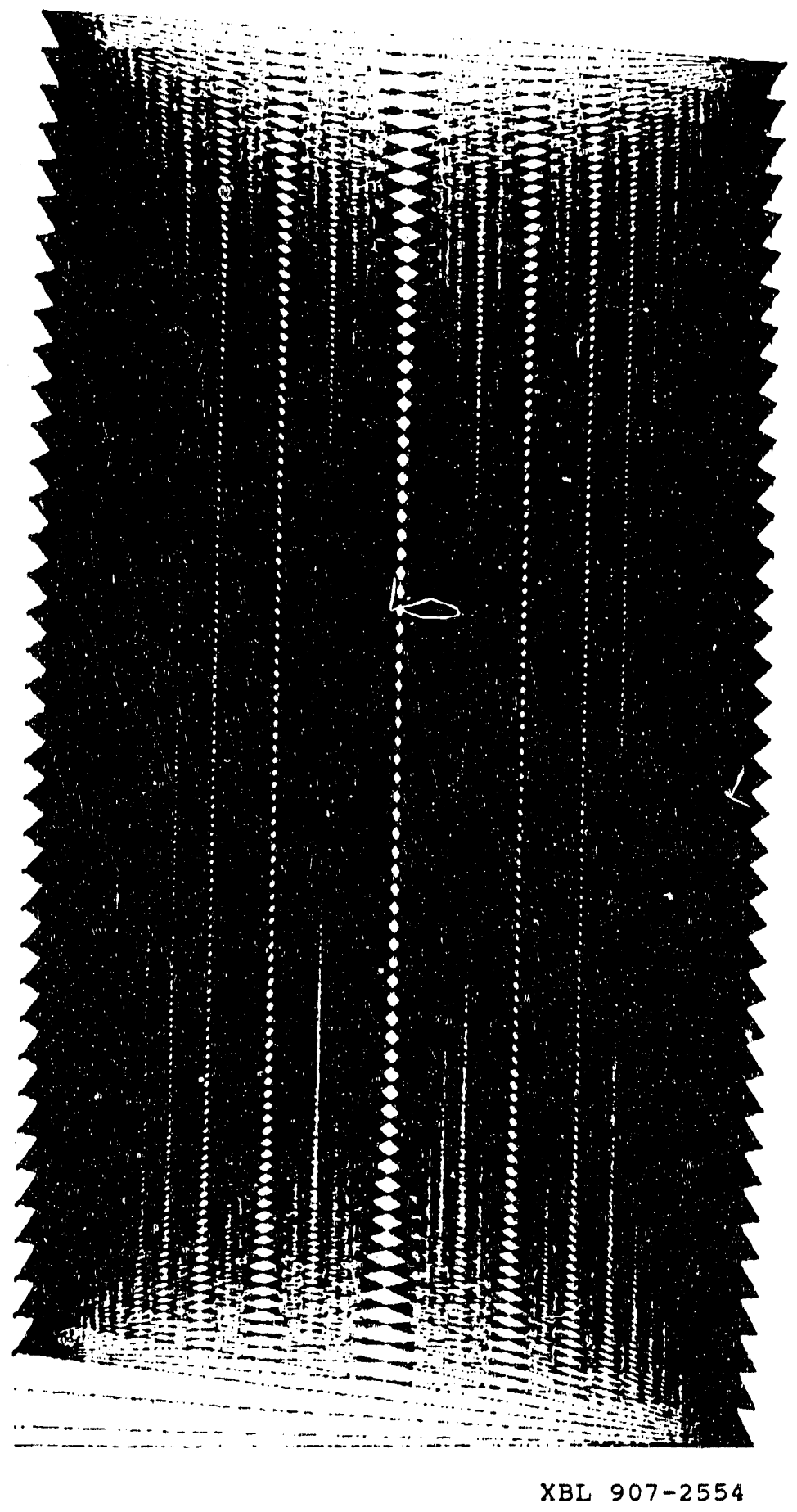

Figure 2.16. The raypaths used for the crosshole inversion. 


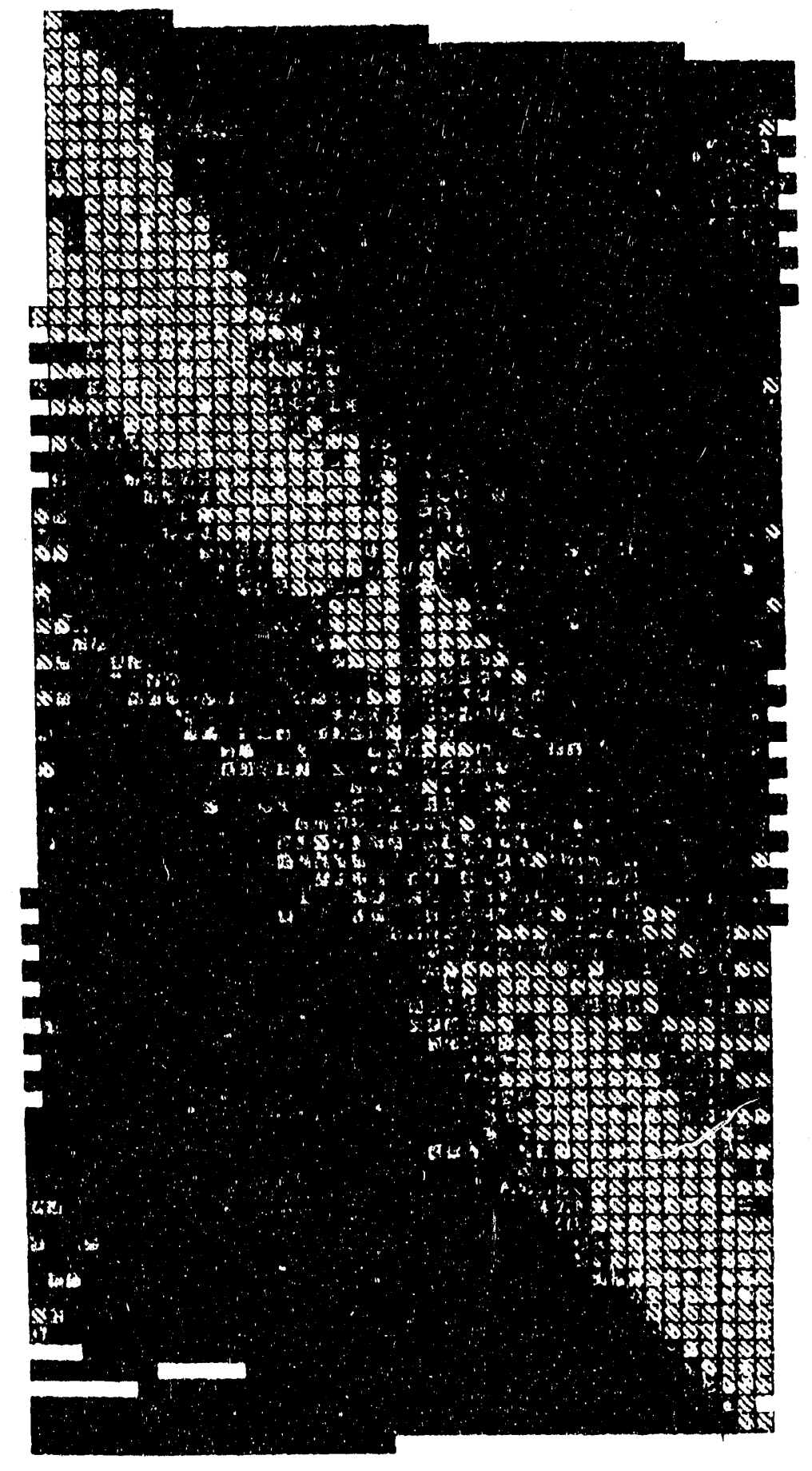

XBL $907 \because 2555$

Figure 2.17. The inversion results using crosshole paths only. 


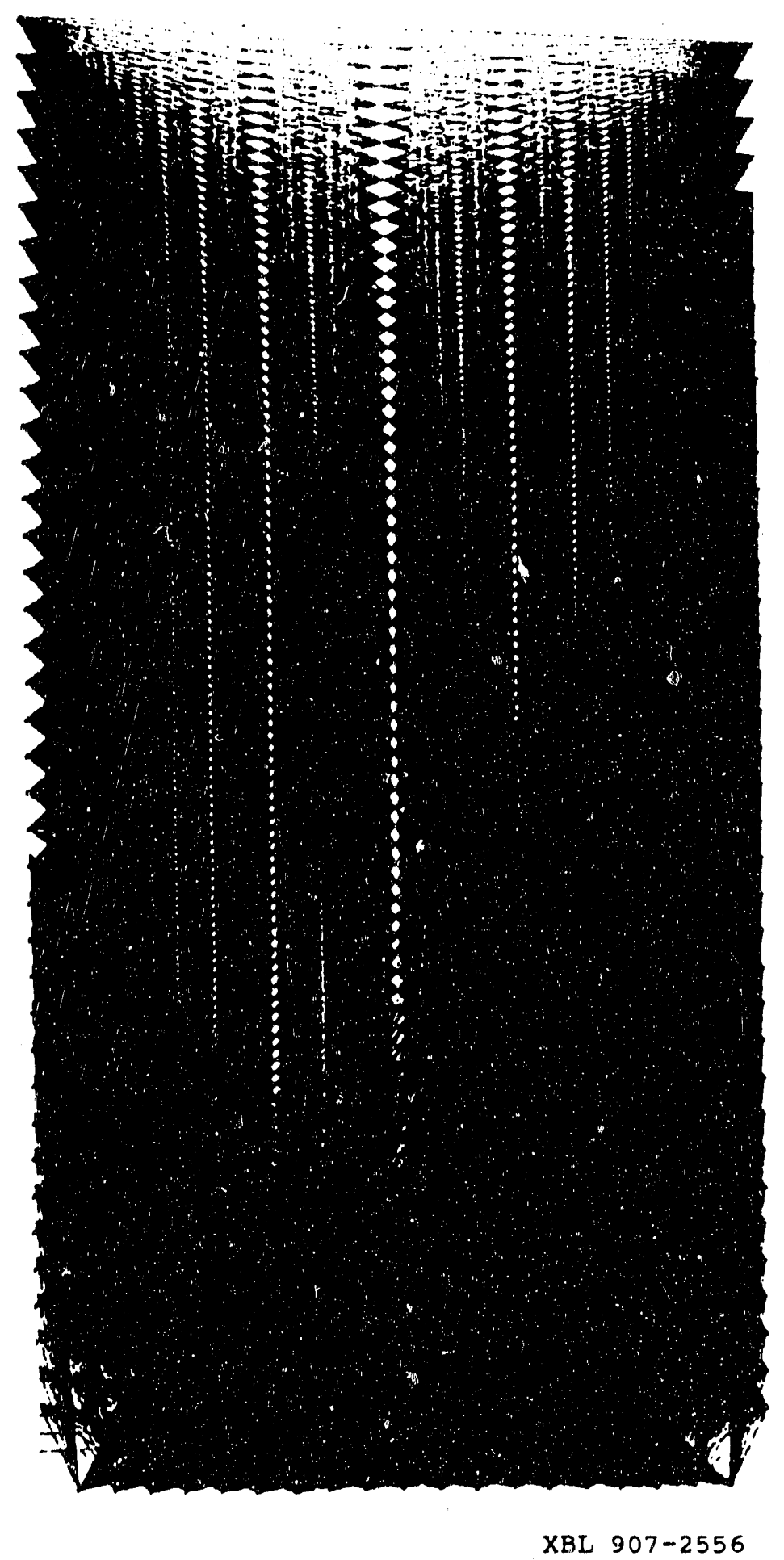

Figure 2.18. The ray paths used for crosshole plus the lab tunnel. 


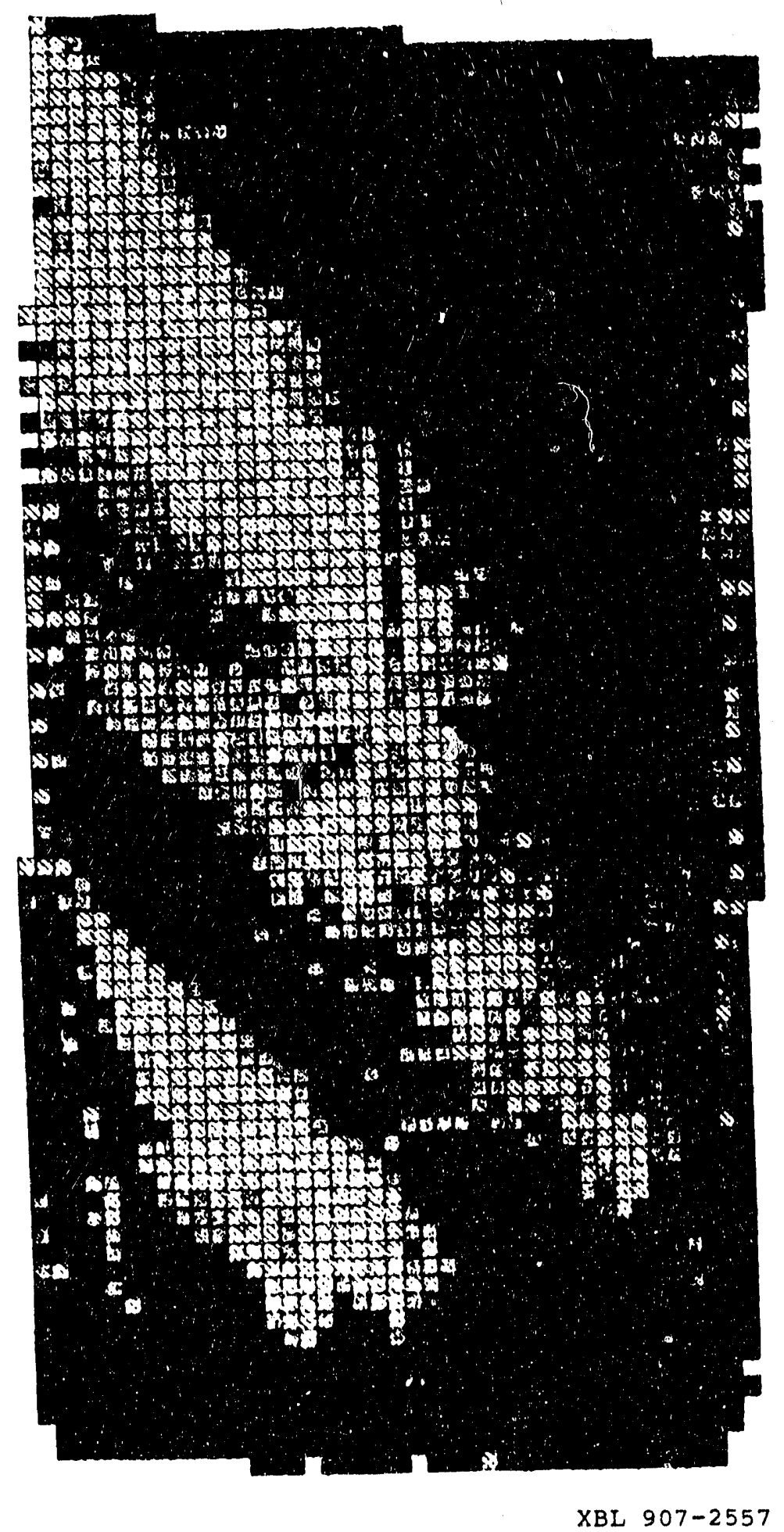

Figure 2.19. The inversion results using the raypaths in Figure 2.18. 


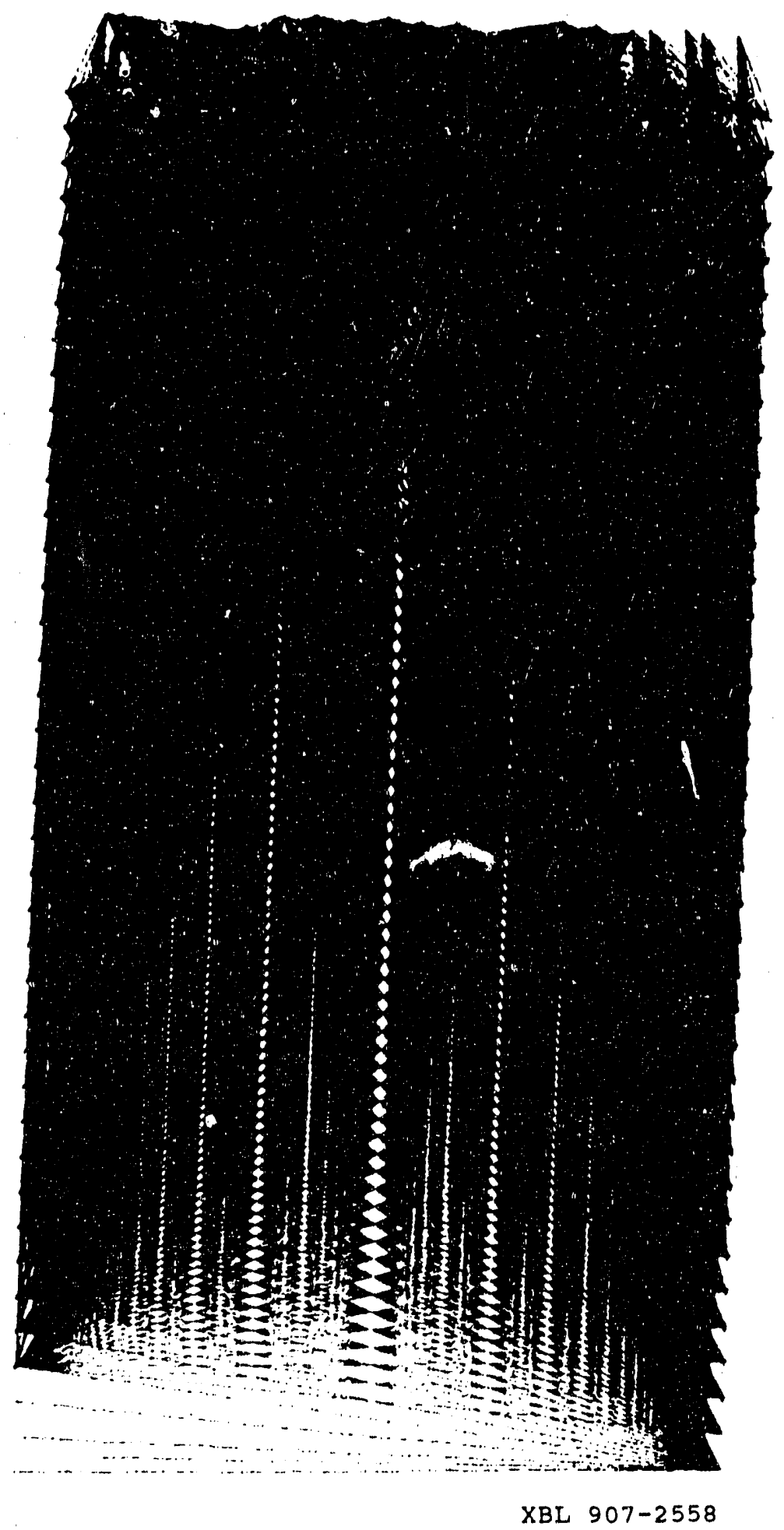

Figure 2.20. The ray paths used for crosshole plus the access tunnel. 


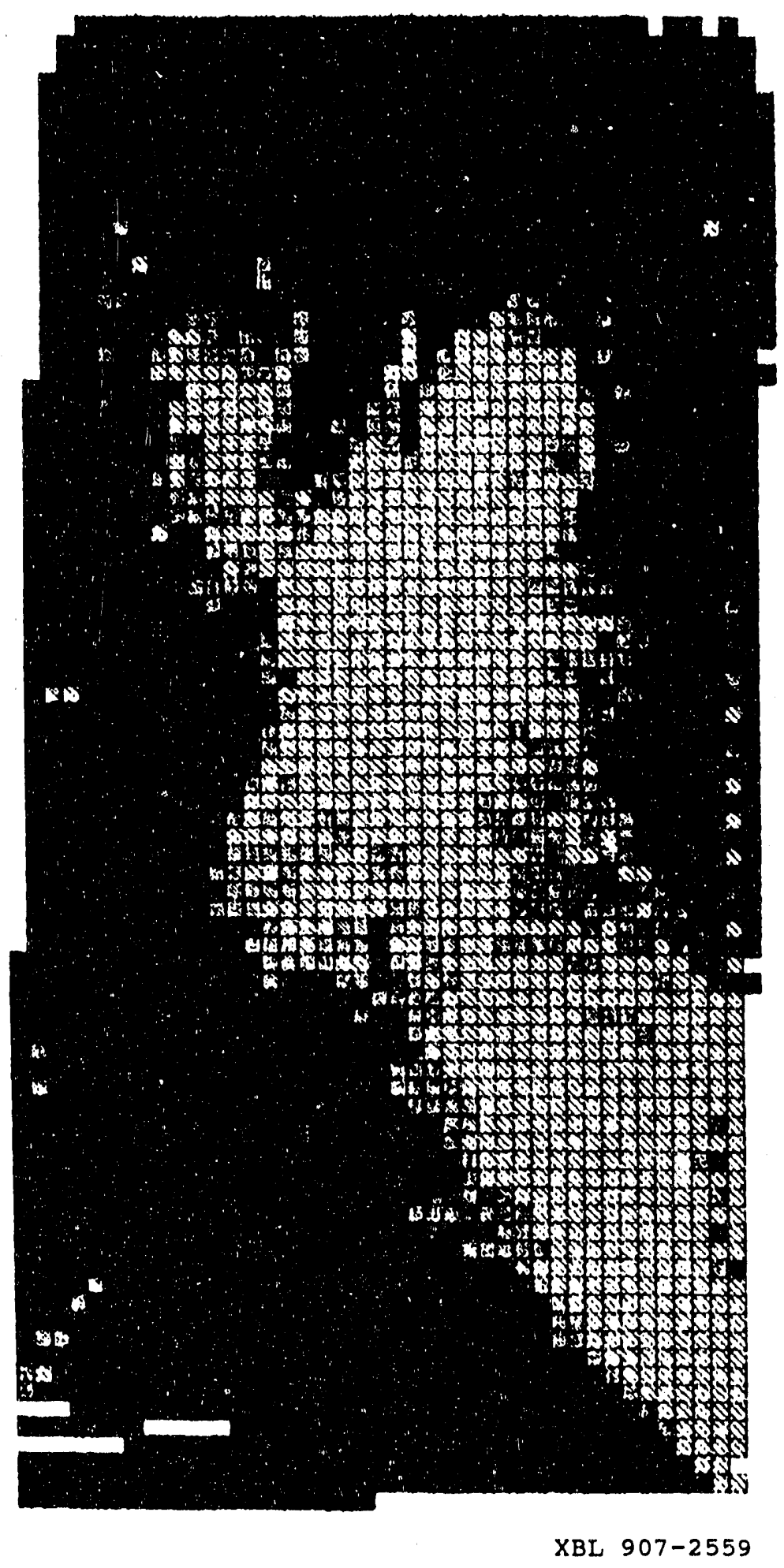

Figure 2.21. The inversion results using the raypaths in Figure 2.20. 


\section{$-31-132$}

tomography the minimum number of sides on which to have coverage is three having this ratio of hole separation. 


\subsection{BK Zone Experilnents}

As stated before, there were two data sets collected during the field work of 1987 at the Grimsel test facility, the FRI zone data set and the BK zone data set. Work in the BK area was done from two diverging boreholes which were 45 meters long with a separation of 2 to approximately 15 meters. These two boreholes intersected several fracture zones and dykes which have been the subject of extensive hydrologic tests. The purpose of the BK seismic study was to gather a limited amount of data to analyze for transmission characteristics for a future detailed study which would closely correlate the seismic parameters to the hydrologic parameters.

The experiment in the BK zone was conducted with the three component receiver in borehole 85.008 and the source down borehole 85.010 . These 45 meter deep boreholes both dip $35^{\circ}$ from the horizontal and diverge at $45^{\circ}$. The holes are initially 1 meter apart at the surface and

diverging towards the ends of the holes (Figure 2.21 shows a plan view from above). Both boreholes were water filled with water slowly flowing from them onto the tunnel floor. The data v/ere collected with the source initially at 28 meters down borehole 85.010 and moved up at 1 meter increments until 5 meters from the top of the hole. We were able to place the receiver at a depth of 39 meters in borehole 85.008. The receiver was also moved up the borehole in one meter increments for each source point until 5 meters from the top of the hole. The signal-tonoise ratio was very good in this area so that the signal could be readily detected over 50 meters with noise consisting of less than 10 percent of the signal.

Because both holes were filled with water we decided that the repeatability of the measurements was good enough to try amplitude analysis. Various methods can be used to pick amplitudes. We chose to take the Fourier transform of the first 90 samples $(1.8$ msecs) after the P energy onset. These values are squared at each frequency, then summed over all frequencies to determine the total P-wave energy. It is not necessary to take the gain or the instrumentation into 
account, because the natural logarithm of the relative amplitude is used in the inversion.

The geometry of this experiment produces a 70 × 70 array of pixels. The Algebraic Reconstruction Technique is used to perform the inversions. The $70 \times 70$ pixel array results in square $0.5 \times 0.5$ meter pixels.

The travel time inversion produces little slowness (or velocity) contrast (Figure 3.1; the shading range is from $4.8 \mathrm{~km} / \mathrm{s}$ (dark) to $5.1 \mathrm{~km} / \mathrm{s}$ (light)). The dominant feature of the velocity reconstruction is a large low velocity zone below 30 meters. Unfortunately, burehole 85.010 is sampled only to 28 meters which means that the extensive low velocity feature can be produced by a single fracture spanning the boreholes. The geometry prevents any sort of resolution of the zone. Another low velocity zone appears at the 20-21 meter level midway between boreholes.

Energy for the attenuation inversion was calculated over the entire spectrum $(0-20 \mathrm{kHz})$ and over bandwidths of $1.0 \mathrm{kHz}$ from 10.0 to $10.0 \mathrm{kHz}$ to improve the resolution of the attenuation features. The inversion equation is

$$
\ln \frac{A_{k}}{A_{0}}=-\int_{R_{k}} \alpha(x, y) d s
$$

where $A_{k}$ is the received energy, $A_{0}$ is the source energy and $\alpha(x, y)$ is the attenuation field. In practice $A_{0}$ must be estimated to be some reasonable value greater than the maximum energy at any receiver. The values are corrected for geometric spreading by multiplication with the ray length.

The amplitude data (Figure 3.3) show much greater contrasts than the travel time data, the shading range is from $0.18 / \mathrm{m}$ (dark - high attenuation) to $0.27 / \mathrm{m}$ (light - low attenuation)). The low velocity zones of Figure 3.1 are better resolved in the attenuation field reconstructions. This agrees with the fracture stiffness theory where the time delay due to a fracture decreases at higher frequencies while the corresponding atienuation increases. A strong attenuation zone is shown at 28 meters down borehole 85.010 which extends halfway across the field. The 21 meter zone is much more distinct and indicative of a fracture zone. It extends from borchole 85.008 to a few meters from borehole 85.010 . A similar zone at 15 meters is also resolved, as well as a few minor 


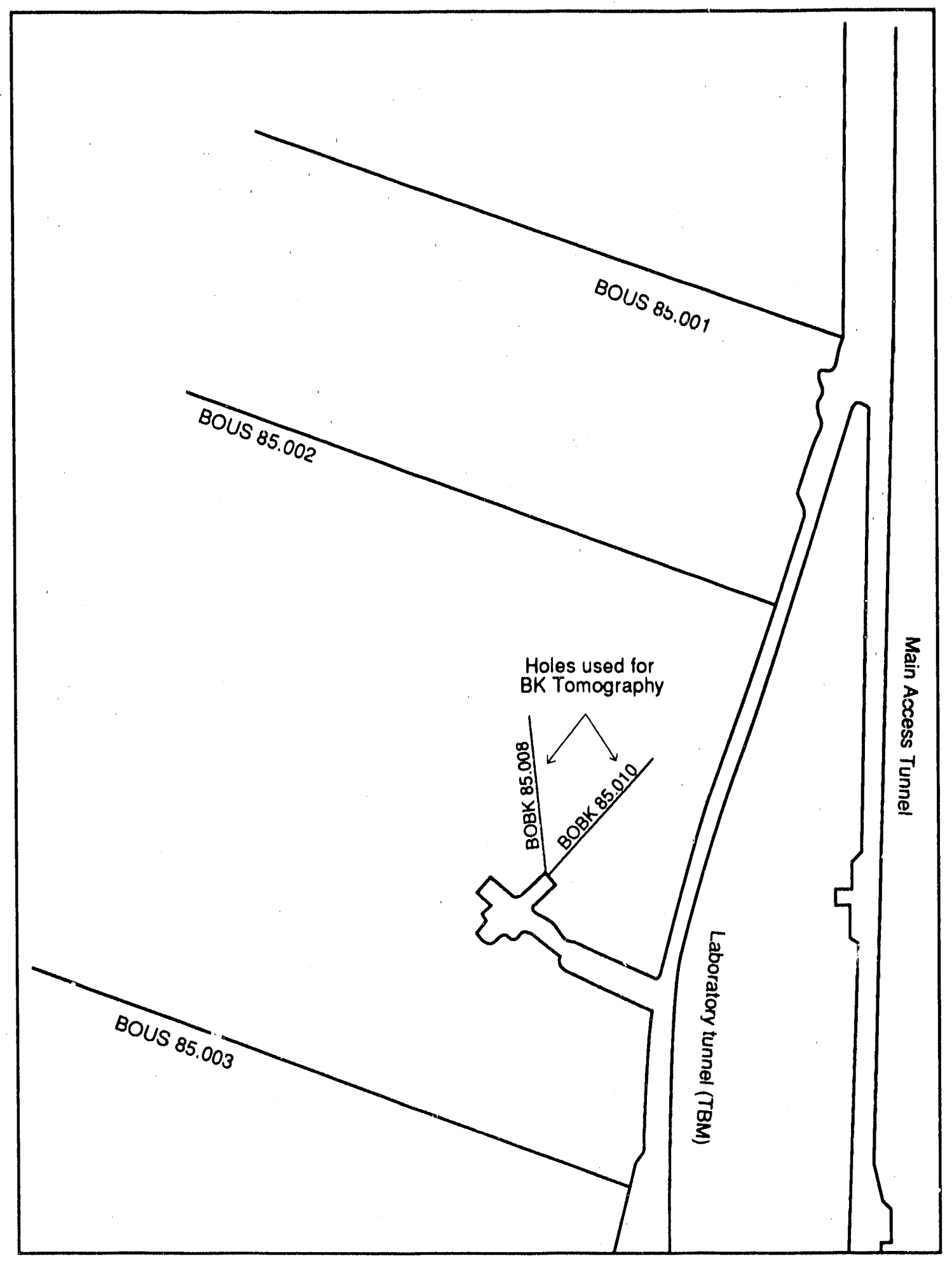

XBL $8911-7897 \mathrm{~A}$

Figure 3.1. Layout of the BK zone boreholes and the boreholes used for the P-wave studics in the $\mathrm{BK}$ zone. 


\section{VELOCITY RECONSTRUCTION}

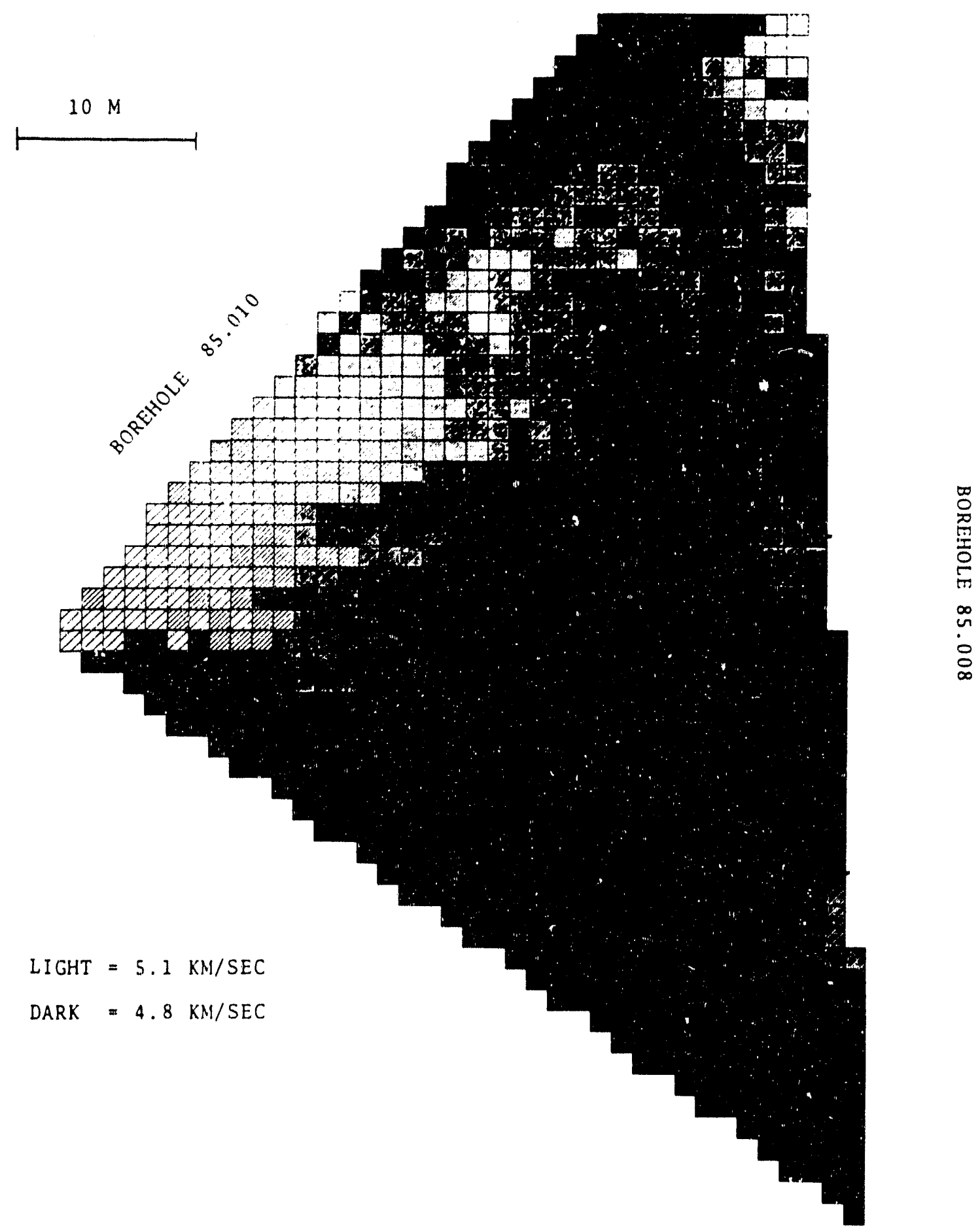

XBI $907-2560$

Figure 3.2. Results of the P-wave velocity tomography in the BK zone. 


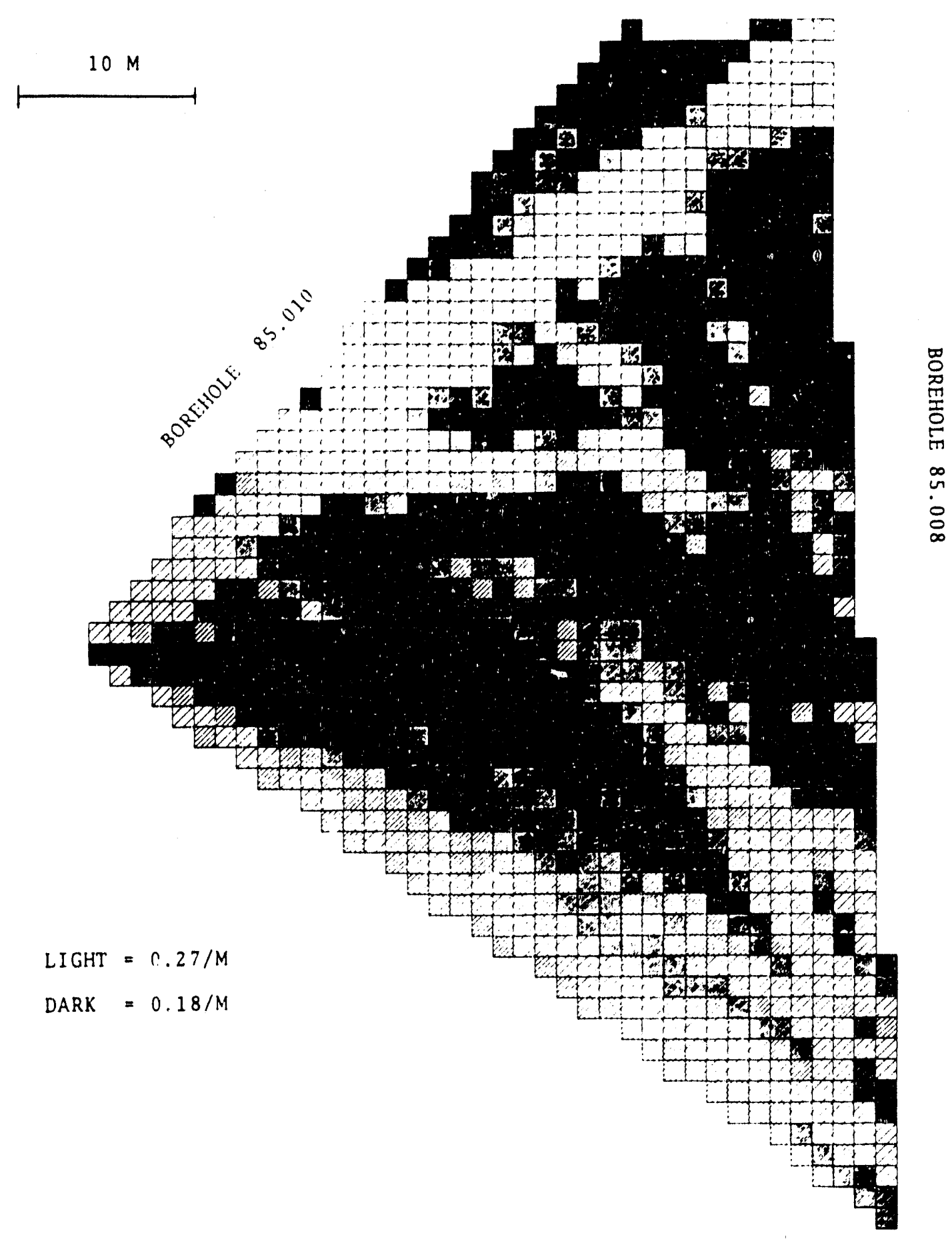

XBL $907-2561$

Figure 3.3. Results of the P-wave amplitude tomography in the BK zone. 
features along the holes.

Moderate smearing decreases the resolution of the amplitude reconstruction. Tube wave energy produces much of this smearing by increasing the energy when they are close enough to the primary to be included in the window. Tube wave spectra is similar to that of the primary arrival eliminating the possibility of easily reducing their effect. The behavior of the primary spectra is dependent on the source/receiver distance. The amount of change in spectra is dependent on the frequency. Energy is calculated from incremental frequency bandwidths of $1.0 \mathrm{kHz}$. The resulting attenuation inversion shows that most information is acquired in the $3-5 \mathrm{kHz}$ and $7-8 \mathrm{kHz}$ range. The remaining frequencies show that higher attenuation occurs when the fracture intersects the boreholes or in areas of borehole damage, and in fact, these areas are the dominant feature of the reconstructed image. This leads to the most common error of interpretation; the smearing of these features between boreholes give the impression of a fracture zone where none may exist.

Zones of attenuation and lower velocity appear to be related to tube wave generation points along the borehole and thus also related to the geology and hydrology. The geometry of the survey was such that the area along the source borehole below 30 meters is poorly resolved due to the inability of the source to progress farther than 28 meters down borehole 85.010 . This prohibits the resolution of the lamphropheres which intersects the boreholes in these areas. The lamphrophere is a zone with the same acoustic characteristics as the surrounding granite, but contains several intertwining fractures. The lamphrophere shows up as an extensive low velocity/high attenuation area below 29 meters. A tube wave is also generated from this area at 32.5 meters down borehole 85.008 . According to the core drawings this corresponds to a mylonite zone within the lamphrophere. The reconstructed attenuation shows the feature extending from borehole 85.010 halfway to borehole 85.008 . The borehole data suggest that these features extends to borehole 85.008 , but the poor sampling and smearing destroy the resolution.

The next zone of interest occurs at 20 to 21 meters. The slowness field shows it as a small, circular low velocity area between the boreholes with a low velocity contrast. The attenuation 
field shows a thin, strong attenuating zone extending from borehole 85.008 to a few meters from borehole 85.010 . A large tube wave is generated from the zone in borehole 85.008 having comparable amplitude as the $\mathrm{P}$ wave. Another, smaller tube wave is generated from the same level in borehole 85.010 . This area corresponds to a known fracture zone as inferred from the core logs. The geology shows a small fracture zone here and the hydrological evidence in the form of flow during pressure from the hydrologic tests. The lack of a hydrologic link in borehole 85.008 suggests that the features are unrelated between boreholes. At 15 meters depth, the attenuation data show another high attenuation zone. There are no detectable tube waves associated with this attenuation anomaly. The only corresponding geological information associated with it is the hydrologic data.

The top of the field is not resolvable due to the smearing of the high attenuation features resulting from the strong tube wave at 21 meters down borehole 85.010 . This is the path of greatest sampling and samples most of the fracture areas. The oscillatory behavior of the inversion in this area also may signal poor inversion results perhaps due to the large range of ray lengths as well as the sampling density. There are two high attenuation field features down borehole 85.008 (Figure 3.2) that correspond nicely with the pair of tube waves also observed at this point. These features are interrupted a few meters from the borehole, then return in the middle of the field only to diminish again. They may be related to the low velocity/high attenuation zone toward the top of borehole 85.010 . This zone also corresponds to an area of flow in the injection experiment at 20 bars overpressure.

In general we were very encouraged with the results from the BK zone. The results indicate that features such as significant fracture zones and changes in rock type are very distinguishable by using $\mathrm{P}$-wave seismic tomography. Amplitudes are much more sensitive to these changes than velocities. 


\subsection{Summary}

The results of the field work to date indicate that the original premise of using P- and Swaves for mapping fracture content is valid. The main fracture zone in the FRI zone was detected using $\mathrm{P}$-wave tomography. The S-wave was attenuated so strongly by the fractures that there was not enough data to image the fracture zone. Given a strong enough S-wave source one could assume that S-wave data would be even more sensitive to fracture content than P-wave data. Other low velocity zones in the FRI area were also detected, the most significant being the velocity anomalies associated with the stress relief at the tunnel wills. This work is rather conclusive in showing the difference in the damage zone between a tunnel excavated with a tunnel boring machine and a tunnel excavated by drill and blast. There were also other zones of low velocity detected in the FRI zone, most notably the low velocity zone extending in along borehole 87.002 from the access tunnel approximately 8 meters. This may be due to small fractures, or as laboratory work suggests, a difference in the rock type. The core do not show significant fracturing in this zone, but the core velocities are lower for this type of rock than for the rock in the high velocity zone. Work at the BK site showed that given consistent coupling, amplitude data could be useful. This is very significant because of the greater sensitivity of the amplitudes to fracture content than the travel times.

Future work should focus on using improved shear wave data for improving the resolution of the technique and for defining such parameters as fracture density and spacing using multicomponent data. 


\subsection{References}

Crampin, S., 1978. Seismic-wave propagation through a cracked solid: polarization as a possible dilatancy diagnostic, Geophys. J. Roy. Astron. Soc., 53, 467-496.

Crampin, S., 1981. A review of wave motion in anisotropic and cracked elastic-media, Wave Motion, 3, 343-391.

Crampin, S., 1984a. Effective anisotropic propagation through a cracked solid, In Crampin, S., Hipkin, R. G., and Chesnokov, E. M., eds., Proc. of the First Internat. Workshop on Seismic Anisotropy, Geophys. J. Roy. Astron. Soc., 76, 135-145.

Crampin, S. 1984b. Anisotropy in exploration seismics, First Break, 2, 19-21.

Crampin, S. 1985. Evaluation of anisotropy by shear wave splitting, Geophysics, 50, (1) 142-152.

Hopkins, D. L., N. G. W. Cook, and L. R. Myer, 1987. Stress stiffness and aperture as a function of applied stress and contact geometry, Proc. 28th Symp. on Rock Mechanics, University of Arizona, Tucson, Arizona, June 29-July 1.

Kanasewich, E. R., 1975. Time sequence analysis in geophysics, The University of Alberta Press, Edmonton, Alberta.

Leary, P. C. and T. L. Henyey, 1985. Anisotropy and fracture zones about a geothermal well from P-wave velocity profiles. Geophysics, 50, (1) 25-36.

Schoenberg, M., 1980. Elastic wave behavior across linear slip interfaces, J. Acoust. Soc. Am., $68,(5) 1516-1521$.

Schoenberg, M., 1983. Reflection of elastic waves from periodically stratified media with interfa. cial slip, Geophys. Prosp., 31, 265-292.

Stewart, R. R., R. M. Turpening, and M. N. Toksoz, 1981. Study of a subsurface fracture zone by vertical seismic profiling, Geophys. Res. Lett., 8, 2132-1135. 

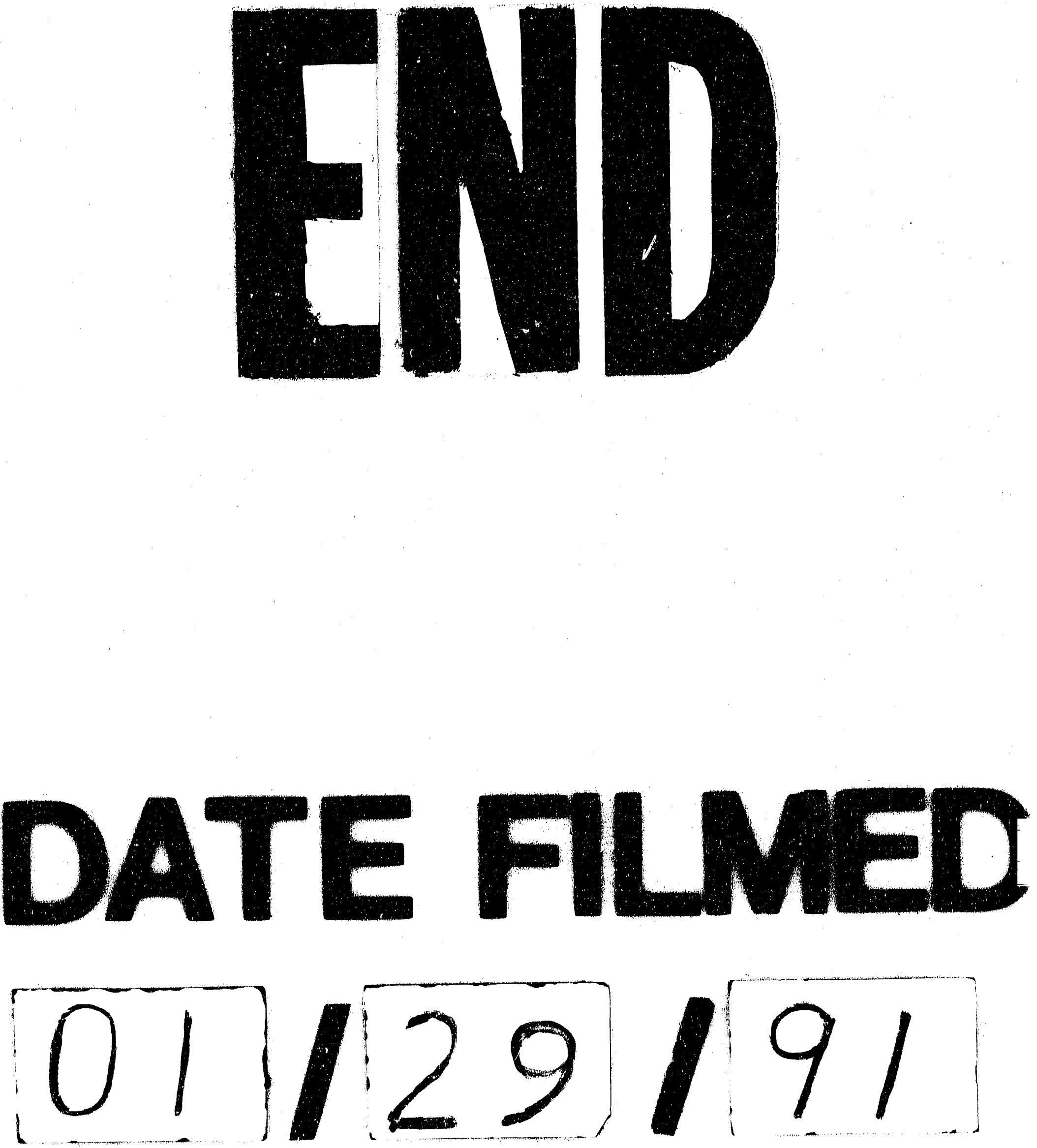
